\title{
Chemically Reacting Plasma Jet Expansion Simulation for Application to Electrothermal Chemical Guns
}

\author{
Andrew J. Porwitzky, Leonardo C. Scalabrin†, Michael Keidar $\ddagger$ and Iain D. Boyd ${ }^{\S}$ \\ Department of Aerospace Engineering, University of Michigan, Ann Arbor, MI 48109
}

\begin{abstract}
A computational fluid dynamics simulation of an expanding capillary plasma jet for electrothermal chemical (ETC) gun application is presented. A chemical model is developed for the plasma-air interaction that uses 26 species and 60 reactions in an implicit CFD code. Time accurate results are obtained for two plasma jet experiments, one with wall impingement with pressure sensor data from multiple locations, and another that decelerated the plasma through a plasma holding chamber, which greatly effected the chemical species present. Conclusions are drawn from the results that speak to the importance of the plasma-air interaction in actual ETC implementation. This work is part of a complete beginning-to-end model of the plasma propellant interaction currently being developed.
\end{abstract}

\section{Nomenclature}

$T \quad$ Temperature in Kelvin

$T_{e} \quad$ Electron temperature in $\mathrm{eV}$

$u \quad$ Flow speed in $\mathrm{m} / \mathrm{s}$

$\rho \quad$ Mass density in $\mathrm{kg} / \mathrm{m}^{3}$

$n \quad$ Number density in $\mathrm{m}^{-3}$

$P \quad$ Pressure in $\mathrm{Pa}, \rho \mathrm{RT}$

$P_{a t m}$ Pressure in atmospheres, $\mathrm{P} /(101325 \mathrm{~Pa})$

$X_{m} \quad$ Mole fraction of species $m$

$M \quad$ Mach number, $u / \sqrt{1.4 P / \rho}$

\section{Introduction}

$\mathrm{T}$

HERE has been much interest in recent years in the design and implementation of electrothermal chemical (ETC) guns. An ETC gun is a solid propellant based artillery piece in which the conventional ignition system has been replaced with a capillary plasma source. Among the enhancements encountered in plasma based ignition systems are reduced ignition delay time, highly repeatable ignition time, and enhanced burning and combustion of the solid propellant. ${ }^{1,2}$

Previous work by the authors has looked at the capillary plasma source ${ }^{3}$ and the interaction of the plasma with the propellant grain. ${ }^{4}$ In order to perform accurate modeling of the plasma-propellant interaction (PPI) it is necessary to know which species are reaching the propellant surface. In both experimental setups and final implementation there is the possibility for some plasma-air interaction before the resulting species reach the propellant surface, introducing the possibility that the species coming from the plasma capillary and those interacting with the propellant are not the same. The present study develops a model to determine the effect plasma-air chemistry can have on chemical composition of the plasma.

The LeMANS chemically reacting, parallelized, implicit Navier-Stokes CFD code, developed at the University of Michigan, is used in the present work. LeMANS uses a modified Steger-Warming Flux Vector

\footnotetext{
*Graduate Student, Student Member AIAA. Email: aporwitz@umich.edu

$\dagger$ Graduate Student, Student Member AIAA. Email: lscalabr@umich.edu

¥Assistant Research Scientist, Senior Member AIAA. Email: keidar@umich.edu

${ }^{\S}$ Professor, Associate Fellow AIAA. Email: iainboyd@umich.edu
} 
Splitting scheme for calculation of inviscid fluxes between mesh volumes, is second order accurate in space, and for the purposes of this work time integration is performed using a point implicit method. Further details of the models employed in LeMANS are outlined elsewhere. ${ }^{5,6}$ The code was modified to allow for time varying boundary conditions, namely the capillary plasma inflow. This work represents the first time LeMANS has been used for time accurate or internal flows. The temporal accuracy of LeMANS was verified by simulation of shock tube cases and comparison to an exact Riemann Solver.

Previous work modeling the plasma-air interaction was conducted at the Army Research Laboratory (ARL). In one such simulation and matching experiment ${ }^{7}$ a high pressure plasma jet was fired at a stagnation pressure probe $15 \mathrm{~cm}$ from the capillary inflow. Pressure versus time data were obtained and compared to the simulation. Although accurate pressure probe results were obtained, there are some problems with these previous simulations. The ARL model simulated 38 chemical species, including 16 ionic species. However, a detailed look at the chemistry model ${ }^{8}$ shows that in the 57 reactions there are 12 species that are not included, 10 of which are ionic species. Data was provided for species concentrations at locations between the capillary inflow and the pressure probe. A careful analysis of the species concentrations at the pressure probe shows that there is a strong deviation from quasi-neutrality. The most likely reason for this is that the electrons diffused away at high speed in the simulation. However, since the ARL model contains no electromagnetic terms in the equations governing the fluid calculations, this deviation from quasi-neutrality should not have an effect on the ion flow. The missing electrons will have an effect on the recombination rates at the pressure probe, since there will not be enough electrons to allow ions to recombine. LeMANS is designed to simulate quasi-neutral plasma flows, with an electron diffusion model that maintains quasineutrality. ${ }^{9}$ In all the simulations presented here the deviation from quasi-neutrality was less than $0.01 \%$ everywhere. Since the ARL study is the previous major effort in this field, we felt that for the above reasons that this problem warranted a second look.

Recent experiments of Li et al. ${ }^{11,12}$ have investigated the plasma-air chemistry and the plasma jet in some detail. These experiments include stagnation pressure probe results for a range of capillary-probe distances, propellant sample analysis at a range of capillary-sample distances, sequential photographs of the plasma jet interaction for these cases, and sampling the chemical species present in the jet. The conditions of these recent experiments serve as the basis for the two simulations contained herein.

In Section II we present a short overview of the capillary model in use to generate the plasma inflow. The chemistry model developed is outlined in Section III. Section IV contains an overview of the experiments and how they are adapted to simulation. Section V contains results and discussions, including analysis of each simulation, as well as ways the chemistry model can be reduced to save computational time, and what the simulations indicate about the plasma-air interaction in practical ETC application. We conclude in Section VI.

\section{Capillary Model Inflow}

The plasma inflow is generated via the previously developed capillary model. ${ }^{3,10}$ Both experiments ${ }^{11,12}$ simulated here use the same size capillary $(1.6 \mathrm{~mm}$ internal radius, $26 \mathrm{~mm}$ length) with similar current profiles and peak energy supplied to the plasma generator in each case. The current profile ${ }^{11}$ represents a discharge time of $220 \mu s$ with a peak current of nearly $10 \mathrm{kA}$ occurring at roughly $85 \mu \mathrm{s}$. The current profile was extracted from the publication of Li et al. ${ }^{11}$ via a data stripping code. The electric current input to the capillary model can therefore be considered exact. Figure 1 shows the data points for current obtained by the stripping code.

The one dimensional capillary code solves an ablation model at the polyethylene surface and couples this to a hydrodynamic model to determine capillary exit velocity, density, pressure and temperature. The Saha equation is solved at every cell in the capillary to give the individual densities of hydrogen and carbon ions and atoms, with the electron density determined by the quasi-neutrality condition. Figure 1 shows the polynomial fits to the capillary model results that are input into LeMANS as the inflow pressure and temperature. All species exit the capillary at the electron temperature, which is mostly time invariant at 1.5 $\mathrm{eV}$, or approximately 12,000 Kelvin. The exit boundary condition for the capillary model is sonic flow, with the velocity inflow of LeMANS determined as $\sqrt{\gamma P / \rho}$, with $\gamma=1.4$ assumed. The simulation is not sensitive to this condition, as the jet is a pressure driven flow.

The capillary model output is fit to ninth order polynomials for input into LeMANS. Some of these polynomials give inaccurate values at early times, so a $5 \mu$ s offset is used. This $5 \mu$ s is added back into the 
CFD simulation in post processing in order for the start times to more fully agree with the experiments.

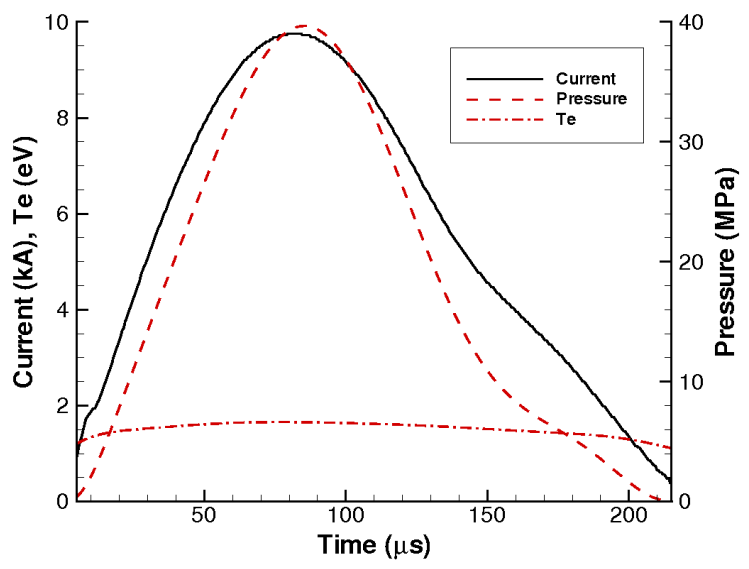

Figure 1. Capillary data.

\section{Chemistry Model}

The chemistry model implemented here is built upon previous work, both theoretical and experimental, on plasma-air chemistry. LeMANS was originally designed for simulating hypersonic flow around reentry vehicles, and uses Park's Model ${ }^{13}$ for nitrogen-oxygen chemistry, the same model used by NASA. ${ }^{6}$ Due to the wide use of this model, it is used for all nitrogen-oxygen chemistry. Additional species are chosen based on the abundances from the ARL simulations, ${ }^{7}$ species with high abundances are chosen first. Due to a desire to compare with the recent measurements of $\mathrm{Li}$ et al. on plasma species present in the jet, ${ }^{12}$ many of the more abundant detected species are added. As a last step, species are added that are needed for extended chemical mechanisms. For instance, to go from $\mathrm{H}$ to $\mathrm{H}_{2} \mathrm{O}$ the species $\mathrm{OH}$ should be added to the model to allow for another reaction path. The total number of species is kept to a minimum to decrease computational expense as the needed resources and computational time can rapidly go beyond practical limits.

The final model arrived at contains 26 chemical species and 60 reactions. The first eleven species are from Park's Model, namely $\mathrm{N}_{2}, \mathrm{O}_{2}, \mathrm{NO}, \mathrm{N}, \mathrm{O}, \mathrm{NO}^{+}, \mathrm{N}_{2}{ }^{+}, \mathrm{O}_{2}{ }^{+}, \mathrm{N}^{+}, \mathrm{O}^{+}$, and electrons (e). The remaining species are $\mathrm{OH}, \mathrm{CO}, \mathrm{CO}_{2}, \mathrm{H}_{2} \mathrm{O}, \mathrm{C}_{2} \mathrm{H}_{2}, \mathrm{C}_{2} \mathrm{H}_{3}, \mathrm{CH}, \mathrm{CH}_{2}, \mathrm{HCO}, \mathrm{NH}, \mathrm{H}_{2}, \mathrm{C}, \mathrm{C}^{+}, \mathrm{H}$, and $\mathrm{H}^{+}$. The $\mathrm{C}_{x} \mathrm{H}_{y}$ species are added because the experiments detected a significant amount of these species. ${ }^{12}$

The reaction rate data is obtained from the GRI-Mech project for all non-Park's Model and non-ion chemistry. ${ }^{14}$ The GRI-Mech data is used in several commercially available hydrocarbon chemistry software packages, including the CHEMKIN software. For the hydrogen and carbon ionization reactions the work of Chang and Ordonez ${ }^{15,16}$ was employed. Table 1 presents a complete list of all reactions used in the simulation. Some of the third body reactions, indicated by the presence of species $\mathrm{M}$, have different reaction rates for a certain M. These species specific rates are also incorporated into LeMANS. All the reactions used have accompanying backward reactions.

Chemical data for each species, such as specific heat, enthalpy of formation, etc, are obtained from GRIMech or Field and Franklin. ${ }^{17}$ Viscosity data for each species are obtained from McBride and Gordon. ${ }^{18}$ Although LeMANS is capable of accommodating a two temperature model, representing translation and vibration, sufficient information could not be found for all chemical species to use this approach. More importantly, due to the high temperatures involved in these flows the translational and vibrational temperatures are nearly equilibrated, rendering a two temperature model unnecessary.

\section{Simulation Methodology}

Two experiments are simulated in the present work. In each experiment, an identical plasma capillary with nearly identical current load was used. Identical capillaries and current loads allow us to use one capillary input for each simulation, thus the main difference between the two simulations is the geometry. 
Table 1. Reactions employed in the chemistry model.

\begin{tabular}{|c|c|c|c|}
\hline Number & Reaction & Number & Reaction \\
\hline 1 & $\mathrm{O}+\mathrm{H}+\mathrm{M} \rightarrow \mathrm{OH}+\mathrm{M}$ & 31 & $\mathrm{HCO}+\mathrm{M} \rightarrow \mathrm{H}+\mathrm{CO}+\mathrm{M}$ \\
\hline 2 & $\mathrm{O}+\mathrm{H}_{2} \rightarrow \mathrm{H}+\mathrm{OH}$ & 32 & $\mathrm{~N}+\mathrm{OH} \rightarrow \mathrm{NO}+\mathrm{H}$ \\
\hline 3 & $\mathrm{O}+\mathrm{CH} \rightarrow \mathrm{H}+\mathrm{CO}$ & 33 & $\mathrm{NH}+\mathrm{O} \rightarrow \mathrm{NO}+\mathrm{H}$ \\
\hline 4 & $\mathrm{O}+\mathrm{CH}_{2} \rightarrow \mathrm{H}+\mathrm{HCO}$ & 34 & $\mathrm{NH}+\mathrm{H} \rightarrow \mathrm{N}+\mathrm{H}_{2}$ \\
\hline 5 & $\mathrm{O}+\mathrm{CO}+\mathrm{M} \rightarrow \mathrm{CO}_{2}+\mathrm{M}$ & 35 & $\mathrm{NH}+\mathrm{OH} \rightarrow \mathrm{N}+\mathrm{H}_{2} \mathrm{O}$ \\
\hline 6 & $\mathrm{O}+\mathrm{HCO} \rightarrow \mathrm{OH}+\mathrm{CO}$ & 36 & $\mathrm{NH}+\mathrm{O}_{2} \rightarrow \mathrm{NO}+\mathrm{OH}$ \\
\hline 7 & $\mathrm{O}+\mathrm{HCO} \rightarrow \mathrm{H}+\mathrm{CO}_{2}$ & 37 & $\mathrm{NH}+\mathrm{N} \rightarrow \mathrm{N}_{2}+\mathrm{H}$ \\
\hline 8 & $\mathrm{O}+\mathrm{C}_{2} \mathrm{H}_{2} \rightarrow \mathrm{CO}+\mathrm{CH}_{2}$ & 38 & $\mathrm{NH}+\mathrm{NO} \rightarrow \mathrm{N}_{2}+\mathrm{OH}$ \\
\hline 9 & $\mathrm{O}_{2}+\mathrm{CO} \rightarrow \mathrm{O}+\mathrm{CO}_{2}$ & 39 & $\mathrm{C}+\mathrm{NO} \rightarrow \mathrm{CO}+\mathrm{N}$ \\
\hline 10 & $\mathrm{H}+\mathrm{O}_{2} \rightarrow \mathrm{O}+\mathrm{OH}$ & 40 & $\mathrm{~N}+\mathrm{CO}_{2} \rightarrow \mathrm{NO}+\mathrm{CO}$ \\
\hline 11 & $2 \mathrm{H}+\mathrm{M} \rightarrow \mathrm{H}_{2}+\mathrm{M}$ & 41 & $\mathrm{CH}_{2}+\mathrm{O}_{2} \rightarrow 2 \mathrm{H}+\mathrm{CO}_{2}$ \\
\hline 12 & $\mathrm{H}+\mathrm{OH}+\mathrm{M} \rightarrow \mathrm{H}_{2} \mathrm{O}+\mathrm{M}$ & 42 & $2 \mathrm{CH}_{2} \rightarrow 2 \mathrm{H}+\mathrm{C}_{2} \mathrm{H}_{2}$ \\
\hline 13 & $\mathrm{H}+\mathrm{CH} \rightarrow \mathrm{C}+\mathrm{H}_{2}$ & 43 & $\mathrm{H}+\mathrm{e} \rightarrow 2 \mathrm{e}+\mathrm{H}^{+}$ \\
\hline 14 & $\mathrm{H}+\mathrm{HCO} \rightarrow \mathrm{H}_{2}+\mathrm{CO}$ & 44 & $\mathrm{C}+\mathrm{e} \rightarrow 2 \mathrm{e}+\mathrm{C}^{+}$ \\
\hline 15 & $\mathrm{H}+\mathrm{C}_{2} \mathrm{H}_{3} \rightarrow \mathrm{H}_{2}+\mathrm{C}_{2} \mathrm{H}_{2}$ & 45 & $\mathrm{O}_{2}+\mathrm{M} \rightarrow 2 \mathrm{O}+\mathrm{M}$ \\
\hline 16 & $\mathrm{OH}+\mathrm{H}_{2} \rightarrow \mathrm{H}+\mathrm{H}_{2} \mathrm{O}$ & 46 & $\mathrm{~N}_{2}+\mathrm{M} \rightarrow 2 \mathrm{~N}+\mathrm{M}$ \\
\hline 17 & $2 \mathrm{OH} \rightarrow \mathrm{O}+\mathrm{H}_{2} \mathrm{O}$ & 47 & $\mathrm{NO}+\mathrm{M} \rightarrow \mathrm{N}+\mathrm{O}+\mathrm{M}$ \\
\hline 18 & $\mathrm{OH}+\mathrm{C} \rightarrow \mathrm{H}+\mathrm{CO}$ & 48 & $\mathrm{NO}+\mathrm{O} \rightarrow \mathrm{O}_{2}+\mathrm{N}$ \\
\hline 19 & $\mathrm{OH}+\mathrm{CH} \rightarrow \mathrm{H}+\mathrm{HCO}$ & 49 & $\mathrm{~N}_{2}+\mathrm{O} \rightarrow \mathrm{NO}+\mathrm{N}$ \\
\hline 20 & $\mathrm{OH}+\mathrm{CH}_{2} \rightarrow \mathrm{CH}+\mathrm{H}_{2} \mathrm{O}$ & 50 & $\mathrm{O}_{2}{ }^{+}+\mathrm{O} \rightarrow \mathrm{O}_{2}+\mathrm{O}^{+}$ \\
\hline 21 & $\mathrm{OH}+\mathrm{CO} \rightarrow \mathrm{H}+\mathrm{CO}_{2}$ & 51 & $\mathrm{~N}_{2}+\mathrm{N}+\rightarrow \mathrm{N}+\mathrm{N}_{2}+$ \\
\hline 22 & $\mathrm{OH}+\mathrm{HCO} \rightarrow \mathrm{H}_{2} \mathrm{O}+\mathrm{CO}$ & 52 & $\mathrm{NO}^{+}+\mathrm{O} \rightarrow \mathrm{NO}+\mathrm{O}^{+}$ \\
\hline 23 & $\mathrm{OH}+\mathrm{C}_{2} \mathrm{H}_{3} \rightarrow \mathrm{H}_{2} \mathrm{O}+\mathrm{C}_{2} \mathrm{H}_{2}$ & 53 & $\mathrm{~N}_{2}{ }^{+} \mathrm{O}+\rightarrow \mathrm{N}_{2}{ }^{+}+\mathrm{O}$ \\
\hline 24 & $\mathrm{C}+\mathrm{O}_{2} \rightarrow \mathrm{O}+\mathrm{CO}$ & 54 & $\mathrm{NO}^{+}+\mathrm{O}_{2} \rightarrow \mathrm{NO}+\mathrm{O}_{2}{ }^{+}$ \\
\hline 25 & $\mathrm{CH}+\mathrm{O}_{2} \rightarrow \mathrm{O}+\mathrm{HCO}$ & 55 & $\mathrm{NO}^{+}+\mathrm{N} \rightarrow \mathrm{N}_{2}^{+}+\mathrm{O}$ \\
\hline 26 & $\mathrm{CH}+\mathrm{H}_{2} \rightarrow \mathrm{H}+\mathrm{CH}_{2}$ & 56 & $\mathrm{~N}+\mathrm{O} \rightarrow \mathrm{NO}^{+}+\mathrm{e}$ \\
\hline 27 & $\mathrm{CH}+\mathrm{CH}_{2} \rightarrow \mathrm{H}+\mathrm{C}_{2} \mathrm{H}_{2}$ & 57 & $2 \mathrm{O} \rightarrow \mathrm{O}_{2}{ }^{+}+\mathrm{e}$ \\
\hline 28 & $\mathrm{CH}+\mathrm{CO}_{2} \rightarrow \mathrm{HCO}+\mathrm{CO}$ & 58 & $2 \mathrm{~N} \rightarrow \mathrm{N}_{2}{ }^{+}+\mathrm{e}$ \\
\hline 29 & $\mathrm{CH}_{2}+\mathrm{O}_{2} \rightarrow \mathrm{OH}+\mathrm{H}+\mathrm{CO}$ & 59 & $\mathrm{O}+\mathrm{e} \rightarrow \mathrm{O}^{+}+2 \mathrm{e}$ \\
\hline 30 & $2 \mathrm{CH}_{2} \rightarrow \mathrm{H}_{2}+\mathrm{C}_{2} \mathrm{H}_{2}$ & 60 & $\mathrm{~N}+\mathrm{e} \rightarrow \mathrm{N}^{+}+2 \mathrm{e}$ \\
\hline
\end{tabular}


The first experiment ${ }^{11}$ fires the plasma into an open chamber at 1 atm pressure. Five pressure sensors are implanted at $9.5 \mathrm{~mm}$ intervals in a wall $40 \mathrm{~mm}$ away, oriented parallel to the exit plane of the capillary. The first pressure sensor is aligned with the capillary exit at the stagnation line, this sensor is labeled P0. Each subsequent sensor is labeled P1-P4, with P4's center being $38 \mathrm{~mm}$ above the capillary center.

Before entering the chamber the capillary plasma travels through a cylindrical nozzle $1.6 \mathrm{~mm}$ in radius and $13 \mathrm{~mm}$ in length. ${ }^{11}$ Since the flow variables could change in this distance, the nozzle is also simulated. The simulation uses an axisymmetric geometry, with the outflow at $\mathrm{y}=50 \mathrm{~mm}$, and walls at $\mathrm{x}=13 \mathrm{~mm}$ and $\mathrm{x}=53 \mathrm{~mm}$. The latter wall contains the five pressure sensors. Pressure versus time data are output at the five "pressure sensors" in the simulation. The P0 sensor is the first wall cell above the symmetry plane, with P1-P4 from wall cells at position $\mathrm{y}=9.5 \mathrm{~mm}, 19 \mathrm{~mm}, 28.5 \mathrm{~mm}$, and $38 \mathrm{~mm}$, respectively. This simulation is labeled below as Case S1.

In the second experiment ${ }^{12}$ the capillary plasma is injected into a cylindrical plasma holding chamber of radius $9.4 \mathrm{~mm}$ and $129.5 \mathrm{~mm}$ length. ${ }^{19}$ Gas escaped the plasma holding chamber through a $0.5 \mathrm{~mm}$ radius nozzle into a 10x10x10 $\mathrm{cm}$ chamber that housed a mass spectrometer probe to measure the species present in the plasma. ${ }^{12}$ The plasma holding chamber was employed in the experiment because the plasma jet washed over the probe too rapidly for any measurements to be made, thus the flow had to be slowed down. Abundances, in terms of arbitrary intensity units, of some species were measured. These arbitrary units make it difficult for exact comparisons to be made, however qualitative comparisons are possible that yield much insight. The simulation of this flow, labeled below as Case S2, has the geometry listed above, with the change that the expansion chamber after the secondary nozzle is not encumbered by the measurement apparatus. This allows for a more direct comparison of the jets in Case S1 and Case S2.

It must be noted that in an attempt to decrease heat loss to the walls the holding chamber in the experiment was lined with polyethylene. However, there is evidence that this liner ablated as far as $50 \mathrm{~mm}$ from the primary nozzle with a total mass loss three to five times that of the mass loss from the capillary. To see what effect this had, the experimenters replaced the polyethylene liner with one of identical dimensions made of aluminum. Their results show that only CO intensity could be accurately measured, with all other chemical species being within the noise level of the measurement. ${ }^{12}$ Essentially, by using a polyethylene liner, the same compound that is ablating in the capillary to form the plasma, the experimenters created a much larger capillary. The higher mass loss due to this wall ablation increases the abundance of carbon and hydrogen in the plasma holding chamber, allowing new reaction mechanisms to occur. This may explain the high abundance of $\mathrm{C}_{x} \mathrm{H}_{y}$ detected in the experiment. The present simulation does not include this ablating holding chamber, and can be thought of as the case with the aluminum liner.

These two simulations allow for some key comparisons to be made concerning the chemistry of the plasma-air interaction. Since the capillary is identical in both experiments, and hence in both simulations, we can compare the chemistry of the primary jet of Case S1 to that of the secondary jet of Case S2, to see the full effect that the holding chamber had. Also, simulating the secondary jet without wall ablation allows us to see how the polyethylene liner skewed the results of the mass spectrometer data. This comparison of the primary and secondary jet chemistry is the main result of the present study.

\section{Results \& Discussion}

\section{A. Analysis of Case S1}

Due to the large computational expense of running a 26 species, chemically reacting CFD simulation, grid convergence was found first for a single species non-chemically reacting flow. This single species had the same inflow temperature, velocity and pressure profile as the full simulation. Grid convergence is based on the arrival time of the pressure pulse at $\mathrm{P} 0$, the value of the peak pressure, and the behavior of the pressure profile just beyond the peak. Case S1 uses rectangular cells with a uniform cell spacing of $\Delta x=0.1 \mathrm{~mm}$, which results in 202,080 cells. Case S1 ran on thirty $2 \mathrm{Ghz}$ processors with a timestep of $\Delta \mathrm{t}=2.5 \times 10^{-9} \mathrm{~s}$, having a total runtime of 296 hours to simulate $70 \mu$ s of real time.

Snapshots of Mach number contours for Case S1 are shown in Fig. 2, where $t=0 \mu \mathrm{s}$ is at the start of the current profile in Fig. 1. For detailed examination of the chemistry we will refer to the data from $t=35$ $\mu \mathrm{s}$. At this time the jet is fully developed, the precursor shock can clearly be seen, and the jet has not yet begun interacting with the wall. Evaluating the chemistry at this time will allow for a much more direct comparison with the secondary jet chemistry of Case S2.

Pressure versus time data are shown in Fig. 3. Experimental data indicates that the precursor shock 


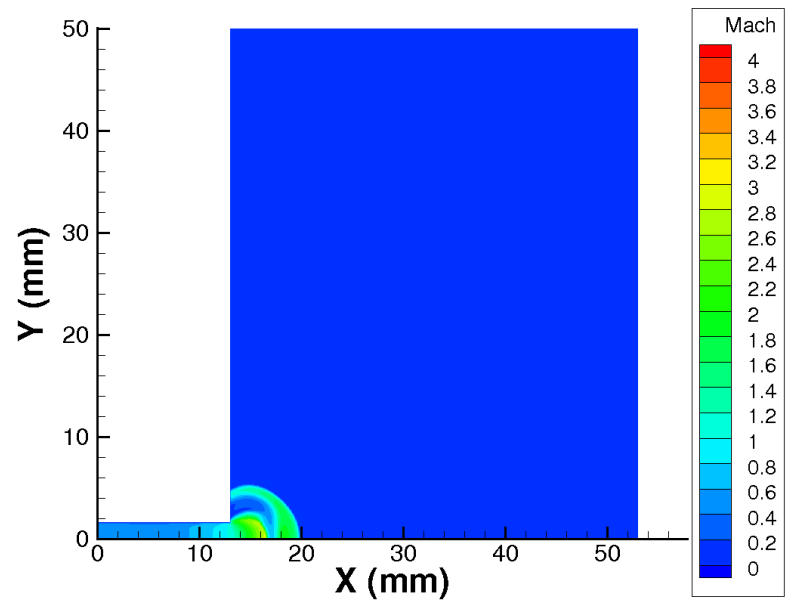

(a) $15 \mu \mathrm{s}$

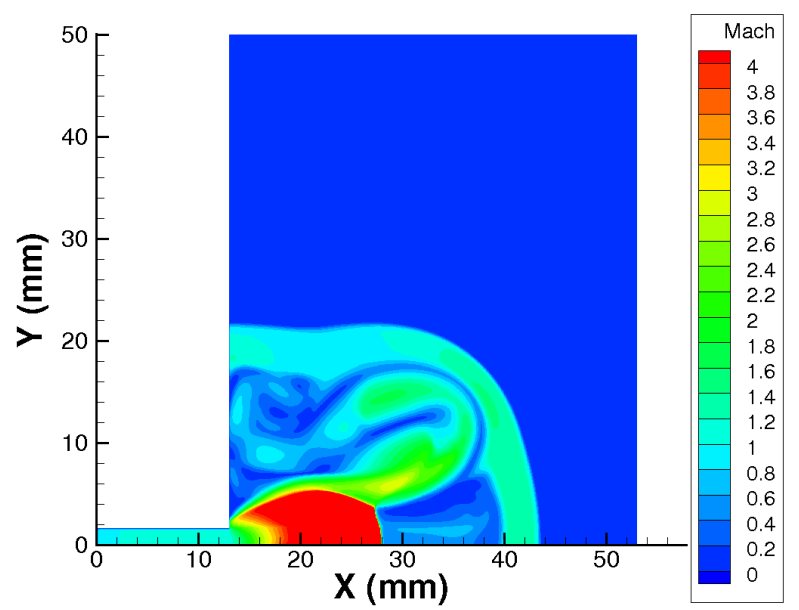

(c) $35 \mu \mathrm{s}$

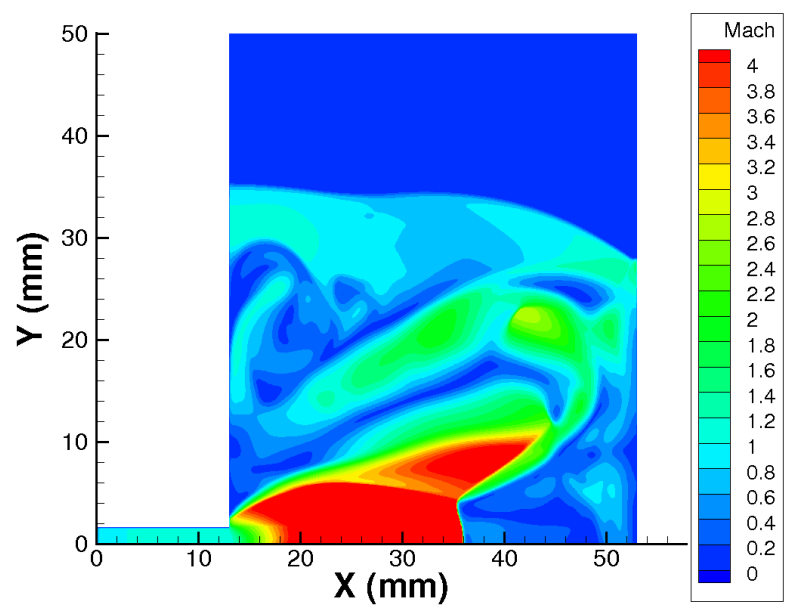

(e) $55 \mu \mathrm{s}$

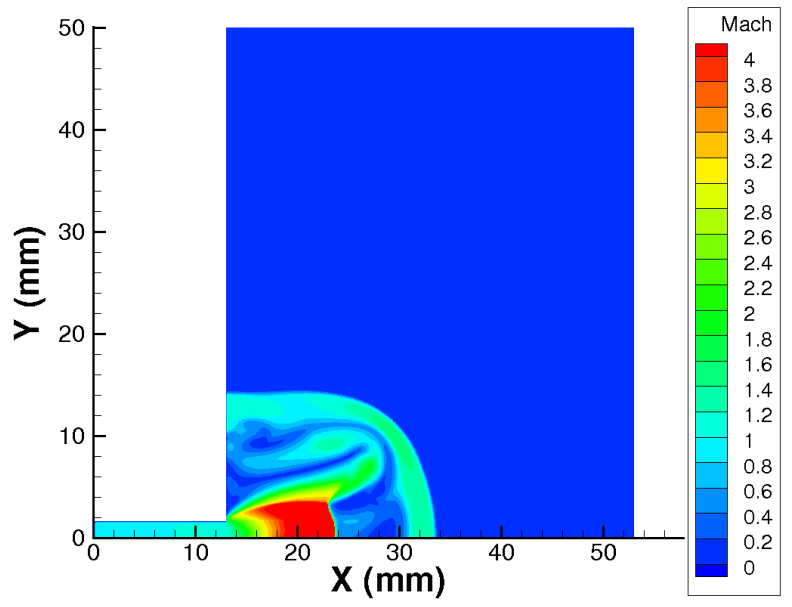

(b) $25 \mu \mathrm{s}$

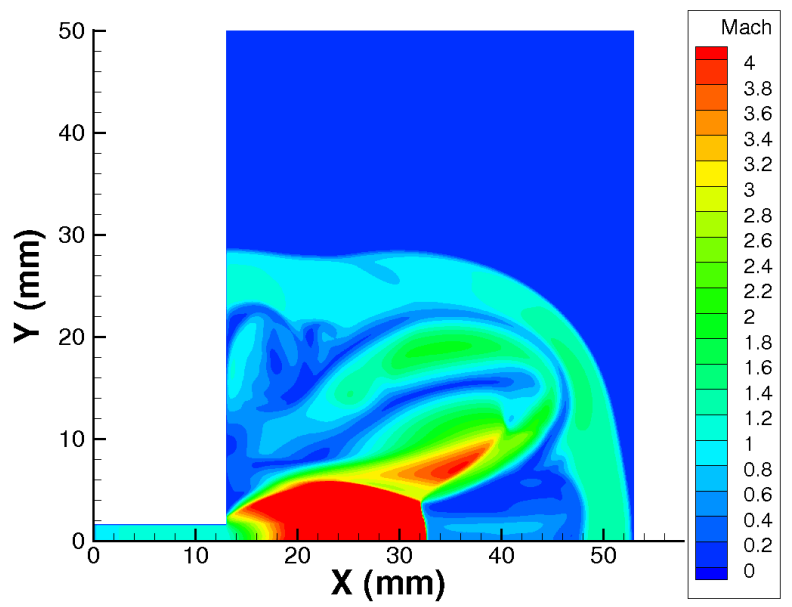

(d) $45 \mu \mathrm{s}$

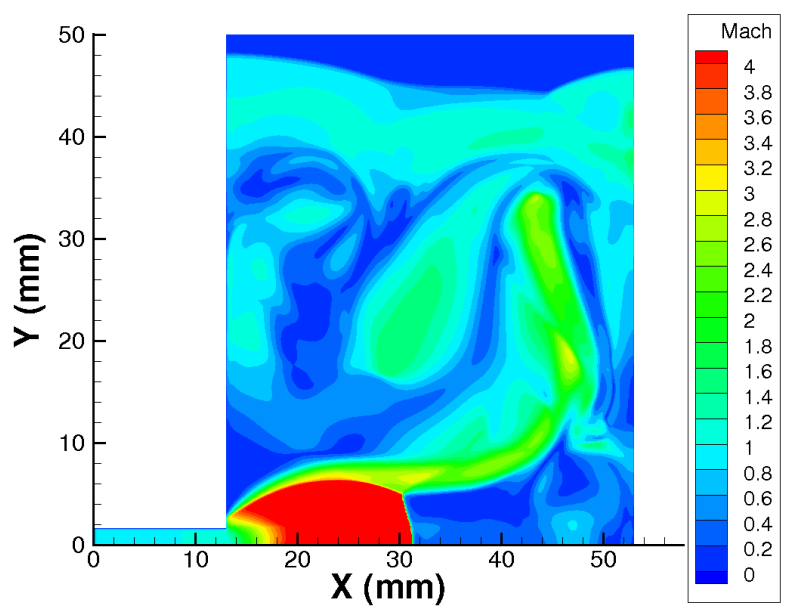

(f) $74 \mu \mathrm{s}$

Figure 2. Snapshots of Mach number for Case S1. 
should arrive at $\mathrm{P} 0$ at approximately $\mathrm{t}=60 \mu \mathrm{s}$, and have a peak of $1.4 \mathrm{MPa}$. The width at half height for the experimental P0 is approximately $20 \mu \mathrm{s} .{ }^{11}$ Case S1 gives a P0 arrival time of $45 \mu \mathrm{s}$, a peak of $3.2 \mathrm{MPa}$ and width of approximately $7 \mu \mathrm{s}$. Experimental data exists for the chamber pressure versus time in the plasma holding chamber of Case S2. ${ }^{12}$ The experiment shows a peak pressure of around 2.5 MPa, whereas Case S2 indicates that chamber pressure can reach more than twice that. This data indicates that perhaps the capillary model is overestimating the pressure. Future work will examine which phenomenon can affect the outflow pressure in the capillary model.

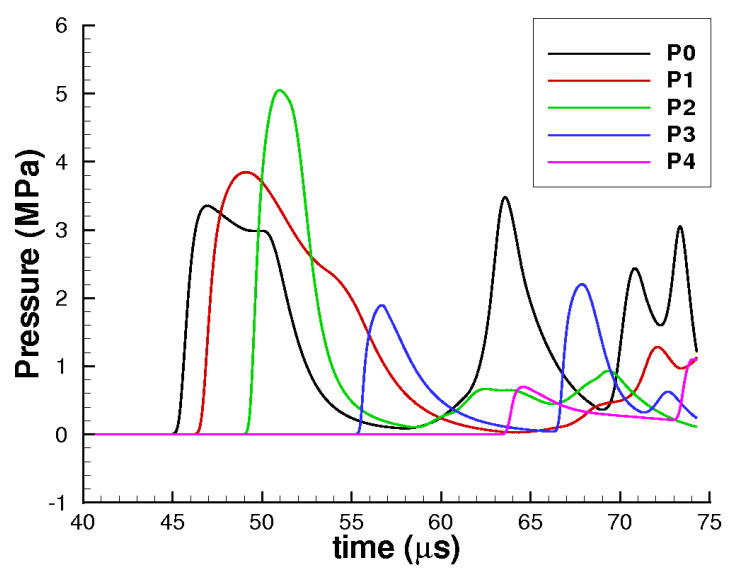

Figure 3. Pressure versus time at the five pressure sensors for Case S1.

In terms of the pressure pulse arriving early in Case $\mathrm{S} 1$ there is a possible explanation beyond the overestimation of the capillary pressure. A change of slope in the current profile is visible in Fig. 1 at approximately $10 \mu \mathrm{s}$. In a typical capillary, an exploding wire is used to create the initial plasma used to trigger the self-sustaining ablation, and this bump is due to the wire exploding. ${ }^{11}$ The capillary code does not model the exploding wire, and instead initializes with a plasma density typical of an exploding wire plasma. With this initial density the capillary begins ablation within the first $3 \mu$ s of the simulation due to the high current load. It is possible that the correct start time would be after the wire explodes, adding a further shift of 10-15 $\mu$ s. This demonstrates how difficult it can be to estimate the start time in this type of simulation. Experimentally it is logical to measure time from the initiation of the current pulse, however the initiation of the current pulse may not correspond to the start of capillary ablation on a timescale of a few microseconds. Further work may be needed to more accurately determine the delay time between initiation of the current pulse and the start of capillary ablation.

Pressure and temperature contours for Case S1 are shown in Fig. 4. The pressure in the capillary nozzle can exceed $180 \mathrm{~atm}$, while the temperature can exceed 17,000 K. Combined with the Mach number contours in the nozzle, it is easy to see that Case $\mathrm{S} 1$ is a pressure driven jet.

Mole fraction contours for selected significant species are shown in Fig. 5. The contour shape of Fig. $5 \mathrm{a}$ is representative of molecular compounds produced by the plasma-air interaction. The products of these reactions are contained in a thin region where the plasma comes in contact with the air, preheated by the precursor shock. Figures 5b-5f show where most of the hydrogen is going chemically. Most of the hydrogen remains atomic, and a significant portion remains ionized in the jet. Very little hydrogen has recombined to $\mathrm{H}_{2}$, the maximum $\mathrm{OH}$ mole fraction is 0.022 , with the peak $\mathrm{H}_{2} \mathrm{O}$ mole fraction below 0.01 . Although chemistry is occurring in the plasma-air reaction zone, the jet remains at such a high temperature that it is still composed primarily of hydrogen and carbon atoms and ions. In the reaction zone, oxygen and nitrogen are heated to a point where atomic oxygen has a peak mole fraction of 0.25 , similarly atomic nitrogen reaches a peak of 0.3. Complex air ion species, such as $\mathrm{NO}^{+}$, remain negligible, with mole fractions below $10^{-5}$. Air ionization reaches a peak mole fraction of 0.01 and 0.003 for $\mathrm{N}^{+}$and $\mathrm{O}^{+}$, respectively.

The main conclusion we can draw from the Case S1 chemistry is that the primary result of the plasma-air reaction in the jet is not the creation of diatomic chemical species, although this does occur to some extent. The main result is ionization and recombination and the dissociation of $\mathrm{O}_{2}$ and $\mathrm{N}_{2}$ into atomic form. As we will discuss later, in practical ETC application the capillary-propellant distance will be minimized, thus we can expect this minimal chemistry to occur. 


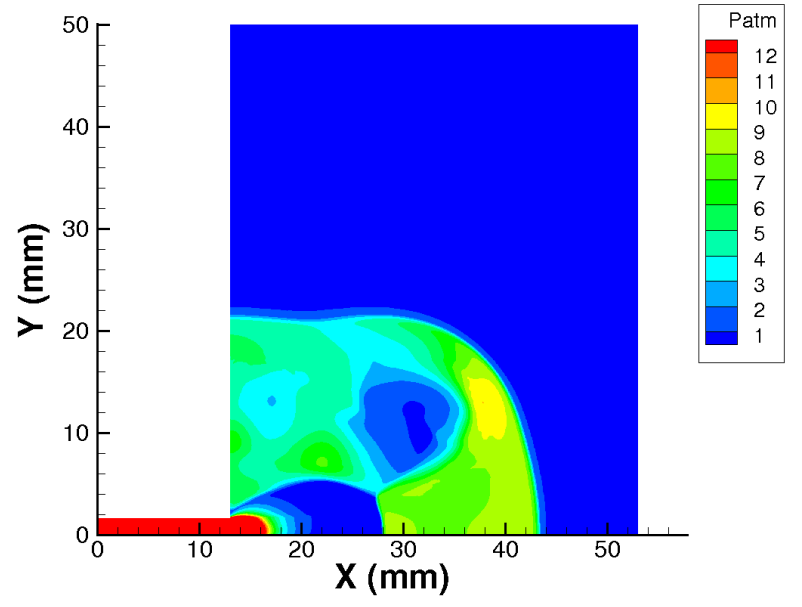

(a) Pressure in atm.

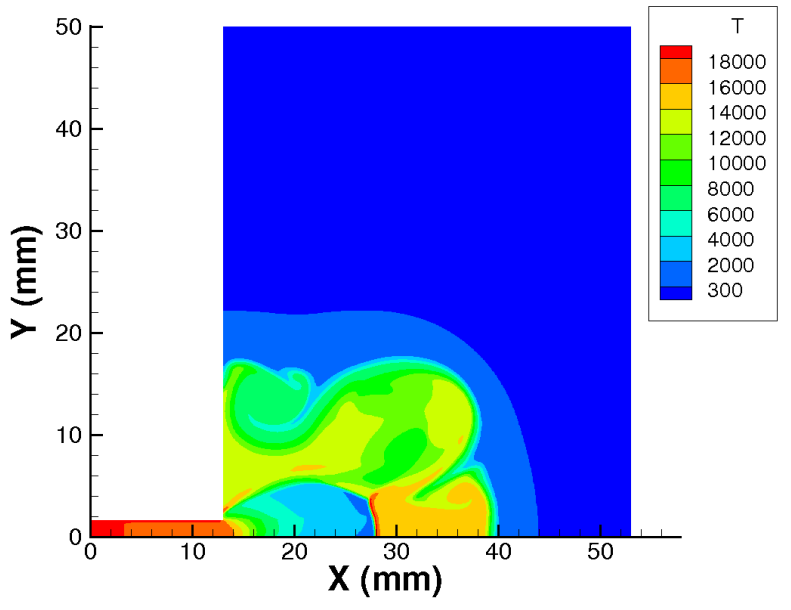

(b) Temperature in Kelvin.

Figure 4. Case $\mathrm{S} 1$ pressure and temperature contours at $\mathrm{t}=35 \mu \mathrm{s}$. 


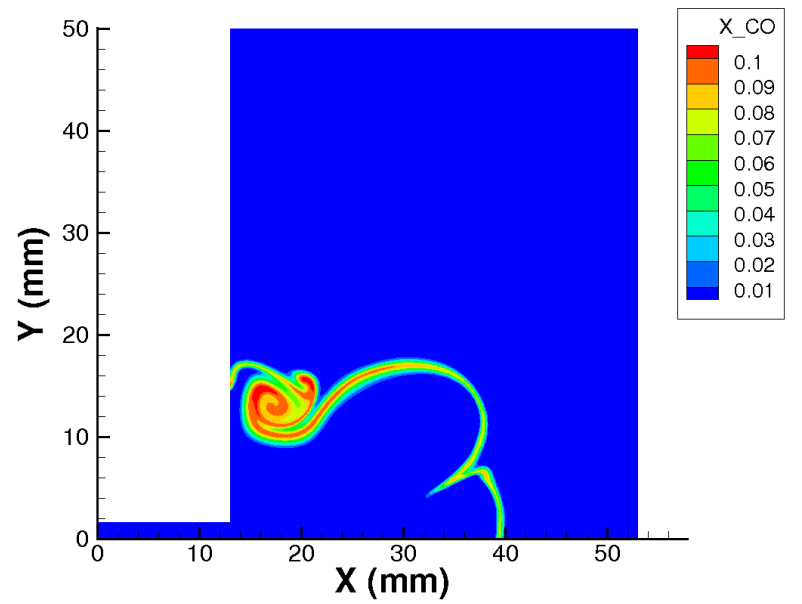

(a) $\mathrm{CO}$

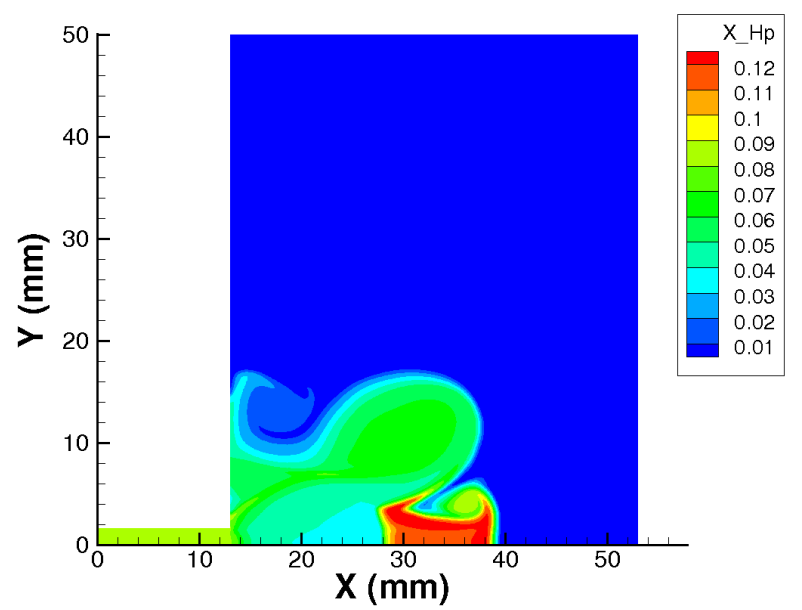

(c) $\mathrm{H}+$

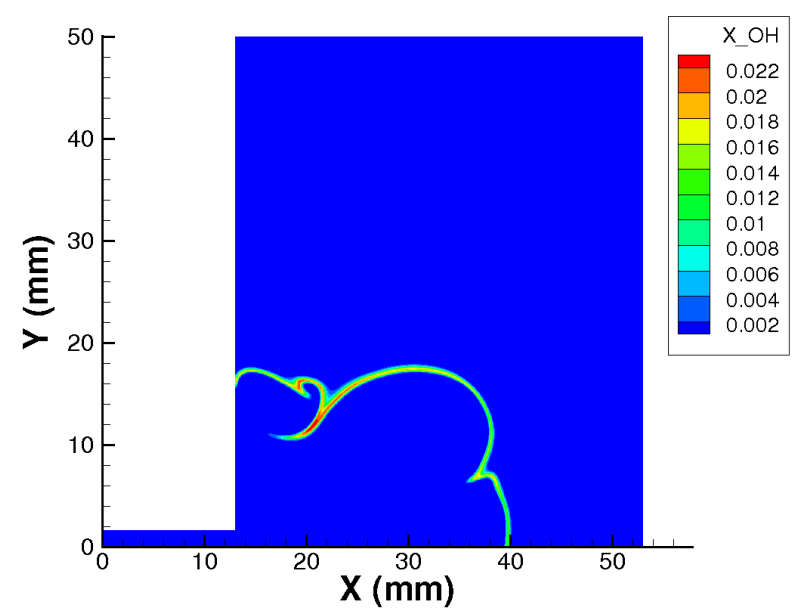

(e) $\mathrm{OH}$

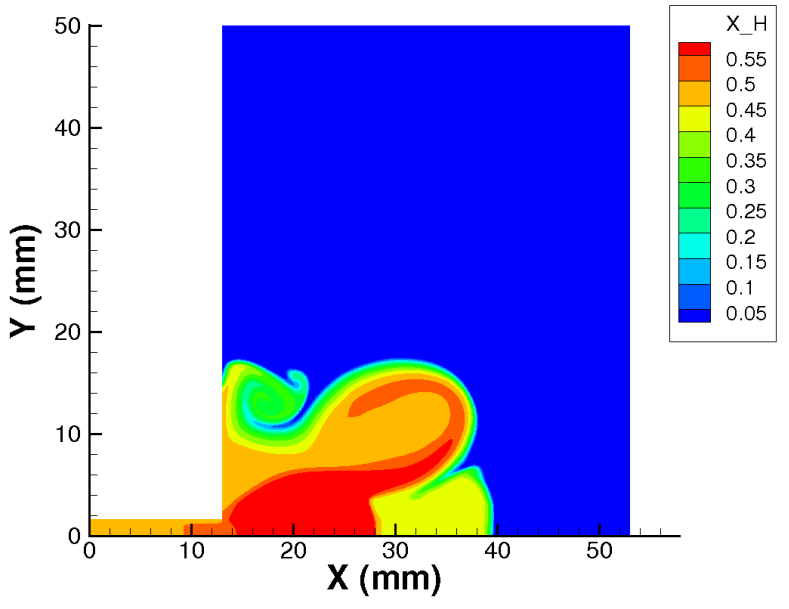

(b) $\mathrm{H}$

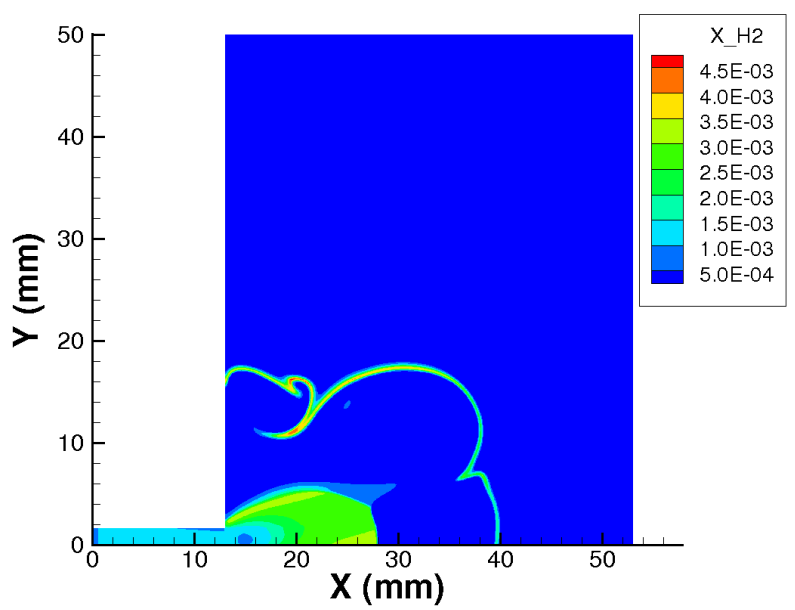

(d) $\mathrm{H}_{2}$

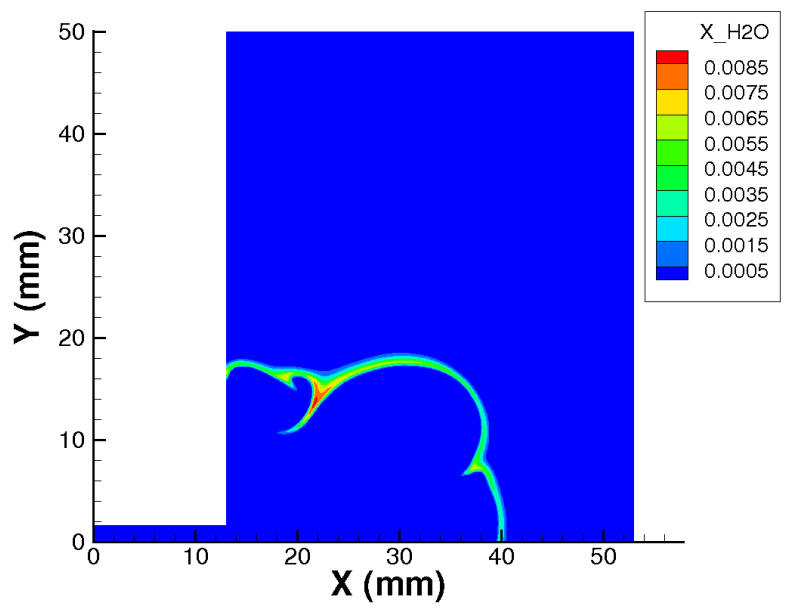

(f) $\mathrm{H}_{2} \mathrm{O}$

Figure 5. Case S1 mole fractions for selected species at $\mathbf{t}=35 \mu \mathrm{s}$. 


\section{B. Analysis of Case S2}

For Case S2 a grid spacing of $\Delta x=0.2 \mathrm{~mm}$ is used, which results in a total of 100,570 grid cells. This allows for faster computational times while still capturing the chemistry. Case S2 also ran on thirty 2 Ghz processors with a timestep of $\Delta \mathrm{t}=5 \times 10^{-9} \mathrm{~s}$, having a total runtime of 174 hours to simulate $110 \mu \mathrm{s}$ of real time.

To provide a sense of scale, Mach number and temperature contours for the entire Case S2 computational domain at $\mathrm{t}=115 \mu \mathrm{s}$ are shown in Fig. 6. Mach number contours for the secondary jet at different flow times are shown in Fig. 7. Chemistry data is referenced to Case S1 at $115 \mu \mathrm{s}$, as the jet is fully developed at this time. The secondary jet emerges from the $1 \mathrm{~mm}$ diameter nozzle 75-80 $\mu$ s after capillary firing. The pressure in the precursor shock behind the nozzle prior to expulsion is approximately $55 \mathrm{~atm}$. As the jet emerges from the second nozzle the temperature drops several thousand Kelvin, as shown in Fig. 8b. At 85 $\mu$ s the pressure in the nozzle is still $50 \mathrm{~atm}$, but this drops to below $7 \mathrm{~atm}$ in the rest of the jet. Figure 8 also shows that although the pressure in the nozzle is still roughly $50 \mathrm{~atm}$, this drops to no higher than 3 atm within $10 \mathrm{~mm}$ of the exit.

The temperature in the bulk of the jet remains below $5,000 \mathrm{~K}$ at all times, with the region farthest from the nozzle typically maintaining a temperature below $3,000 \mathrm{~K}$. With such relatively low temperatures it is not surprising that mole fractions of all ionic species are negligible (below $10^{-10}$ ) in the secondary jet. We also do not see the discrete plasma-air reaction zone that we saw in Case S1, but this is only partially due to the low jet temperature. Because the plasma holding chamber was filled with 1 atm air $\left(0.79 \mathrm{~N}_{2}, 0.21 \mathrm{O}_{2}\right.$ by mole fraction) the plasma-air chemistry was saturated while in the holding chamber. Mach number contours in the holding chamber in Fig. 7 show pulsations, due to compression and expansion waves reflecting from the holding chamber walls. This causes the reaction zone to be perturbed, increasing mixing. For these reasons we can not expect to see the same chemistry, and thus the same reaction products, in the primary jet of Case S1 and the secondary jet of Case S2. Future attempts to measure the species present in the plasma jet must take these considerations into account.

As previously mentioned, in the experiment a polyethylene liner was used in the holding chamber, which drastically increased the hydrocarbon-air ratio in the experiment. This leads to the expected result that the experiment detected far more hydrocarbon and hydrocarbon-air species than are found in Case S2. Figure 9 shows that atomic hydrogen exits the nozzle but as it begins to cool it becomes depleted. Analysis shows that although there is a halo of $\mathrm{H}_{2}$ circling the region of depleted atomic hydrogen with a peak mole fraction of 0.002 , most of the hydrogen goes toward the creation of $\mathrm{OH}$.

Almost the opposite is true for oxygen. There is so much oxygen available thanks to the holding chamber that the atomic oxygen in the jet goes toward essentially every species that contains oxygen, with the limiting factor being the presence of carbon or hydrogen. Figure 10 shows that significant atomic oxygen reaction mechanisms are the recombination to $\mathrm{O}_{2}$, the production of $\mathrm{CO}$, and as this cools the further recombination to $\mathrm{CO}_{2}$. As the atomic oxygen and nitrogen begin to simultaneously cool, they also recombine to form a relatively high amount of $\mathrm{NO}$ in the jet.

It is interesting to note that in the experiment the most abundant species, both with and without the polyethylene liner, was $\mathrm{CO}$. Essentially no $\mathrm{CO}_{2}$ was detected in the experiment, while a large abundance of $\mathrm{C}_{x} \mathrm{H}_{y}$ species was detected. In both Case $\mathrm{S} 1$ and Case $\mathrm{S} 2$, the mole fractions remained below $10^{-7}$ and $10^{-10}$ for $\mathrm{C}_{2} \mathrm{H}_{2}$ and $\mathrm{C}_{2} \mathrm{H}_{3}$, respectively. This disagreement with experiment can not be explained by Case $\mathrm{S} 2$, other than to say that it seams unlikely that $\mathrm{CO}$ would not recombine to $\mathrm{CO}_{2}$ while carbon and hydrogen would form such a large amount of $\mathrm{C}_{x} \mathrm{H}_{y}$ species given the abundance of oxygen. Perhaps the measurement method employed was not particularly sensitive to the presence of $\mathrm{CO}_{2}$, it seams based on the results of Case $\mathrm{S} 2$ and the presence of $\mathrm{C}_{x} \mathrm{H}_{y}$ species in the experiment that most of the $\mathrm{CO}$ should be depleted.

The main conclusion we can draw from the results of Case S2 is that the plasma holding chamber is not a viable option for obtaining measurements of the chemical species present in the plasma jet. The changes in temperature and pressure, as well as the increased interaction time, resulting from the slowing of the flow by the use of a holding chamber means that the species emerging from the secondary nozzle are not directly relateable to the species coming from the capillary.

\section{Simplification of the Chemical Model}

With information from Case S1 and Case S2 it is possible to refine the chemical model. Although the authors feel that the current model captures the major effects in plasma-air chemistry, refinement is possible 


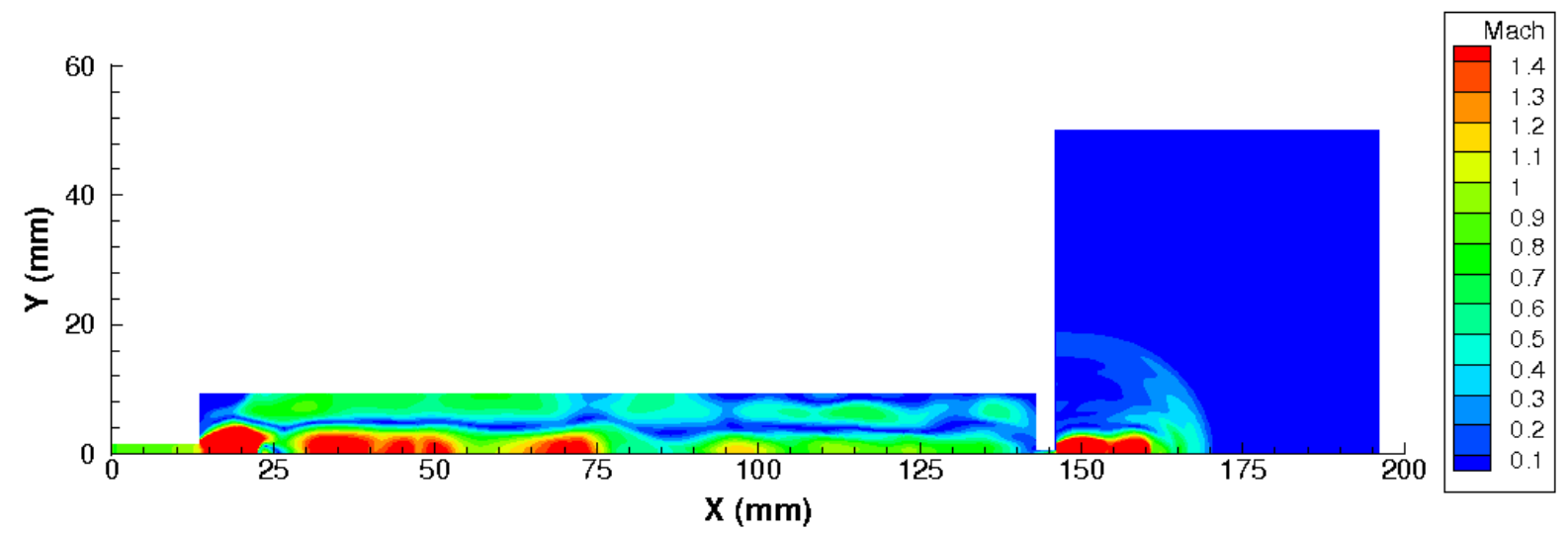

(a) Mach number.

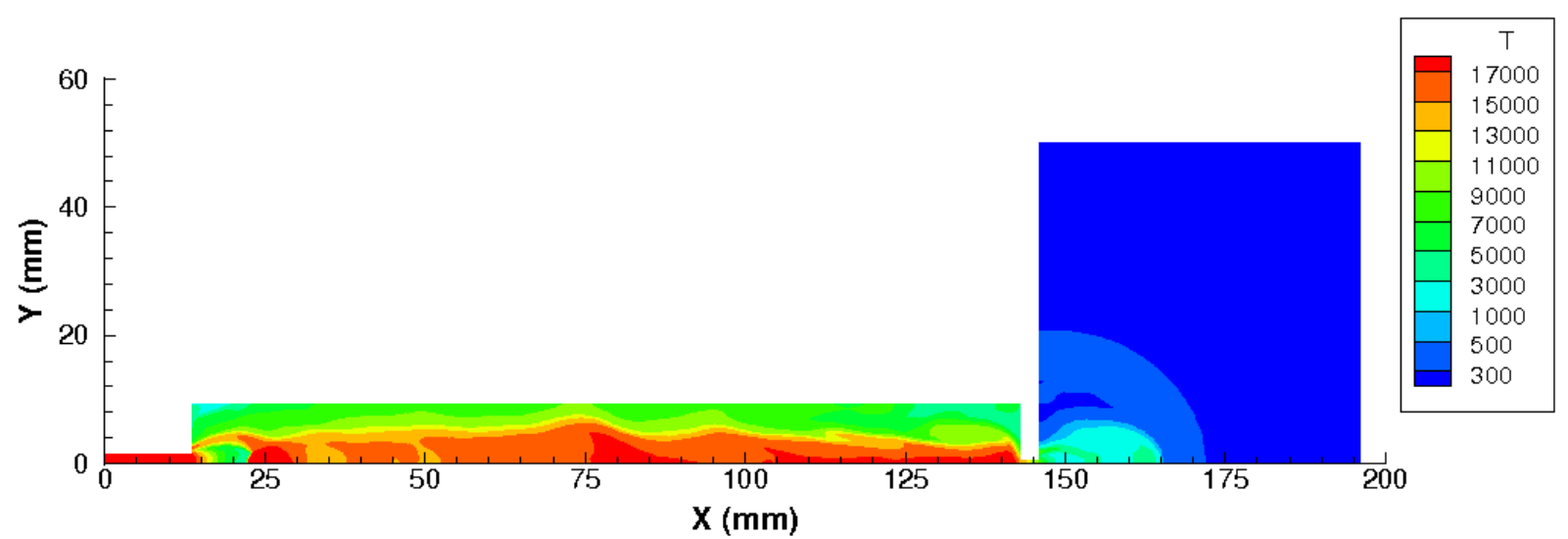

(b) Temperature in Kelvin.

Figure 6. Full computational domain for Case S2 showing Mach number and temperature contours at $\mathrm{t}=115 \mu \mathrm{s}$. 


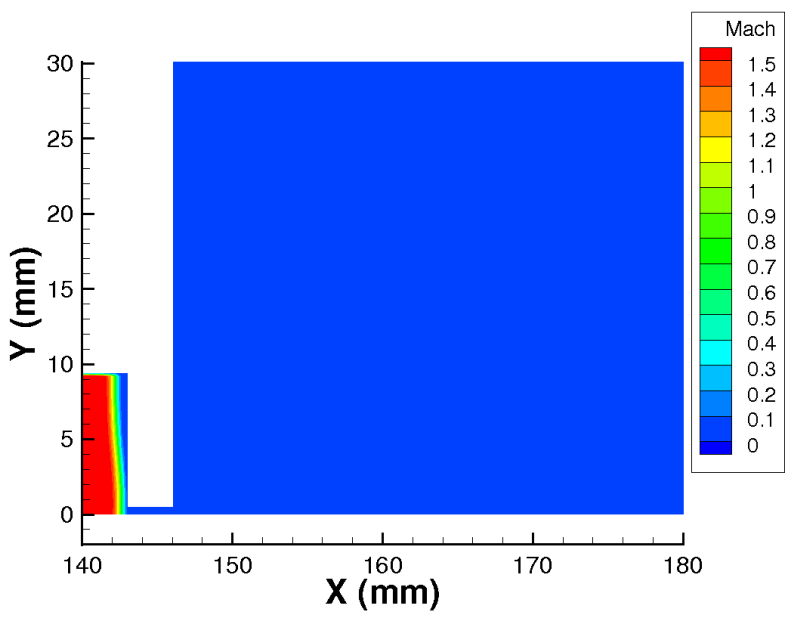

(a) $75 \mu \mathrm{s}$

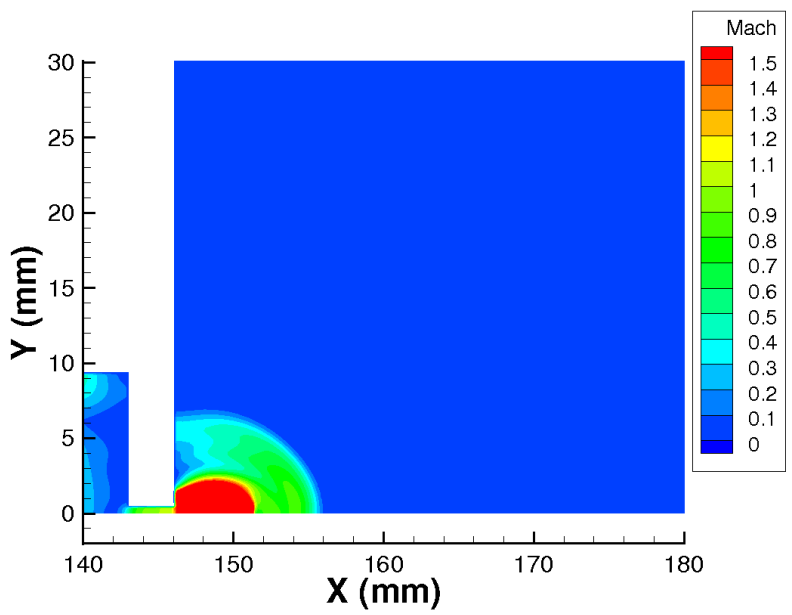

(c) $85 \mu \mathrm{s}$

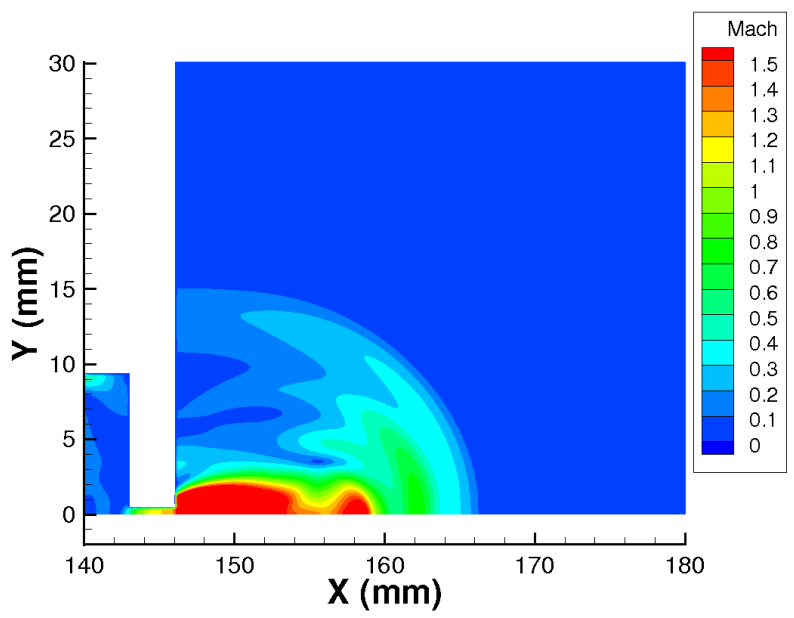

(e) $105 \mu \mathrm{s}$

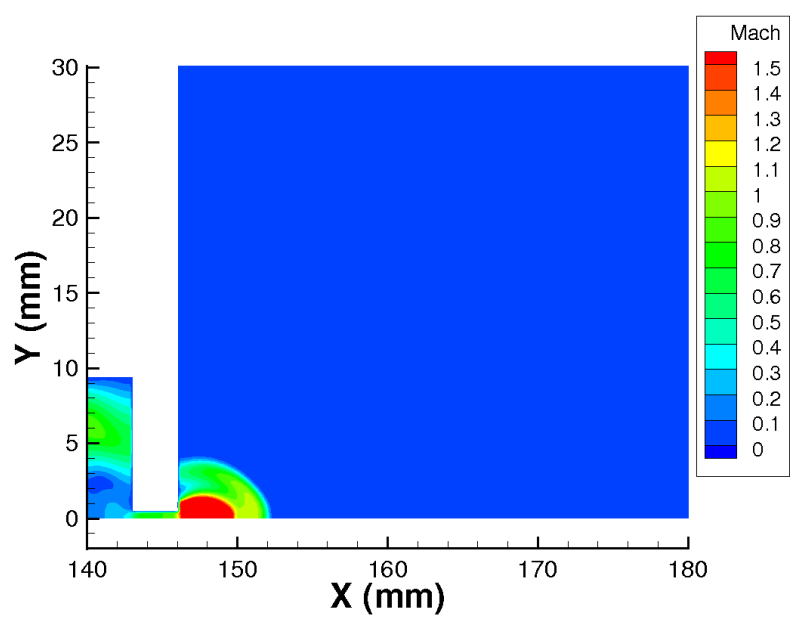

(b) $80 \mu \mathrm{s}$

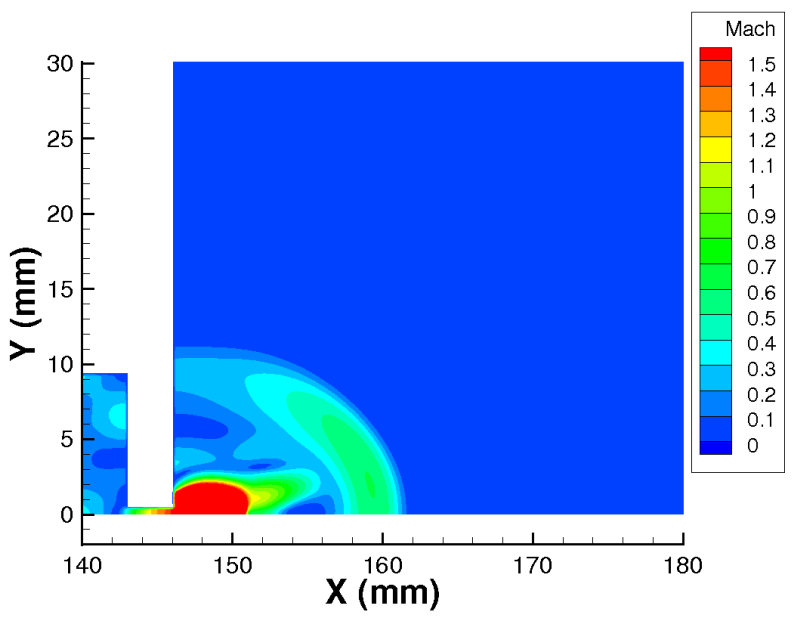

(d) $95 \mu \mathrm{s}$

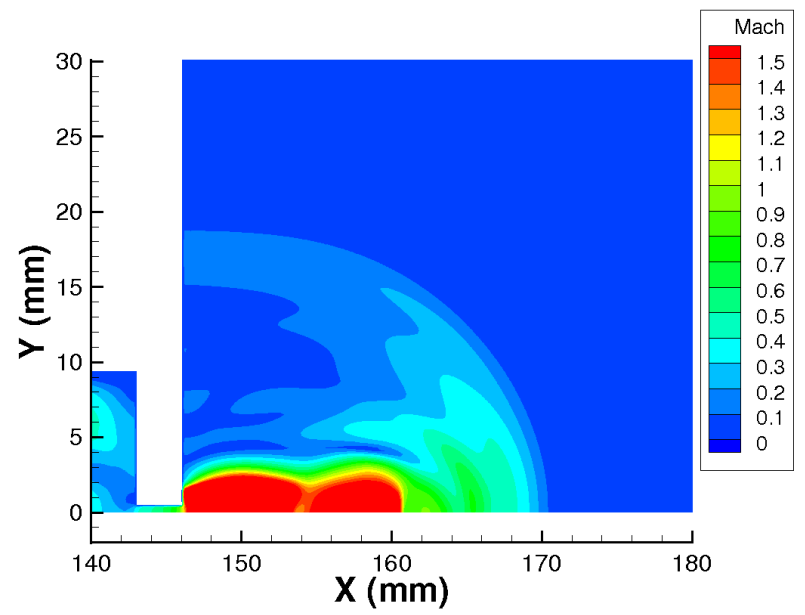

(f) $115 \mu \mathrm{s}$

Figure 7. Snapshots of Mach number for the Case S2 secondary jet. 


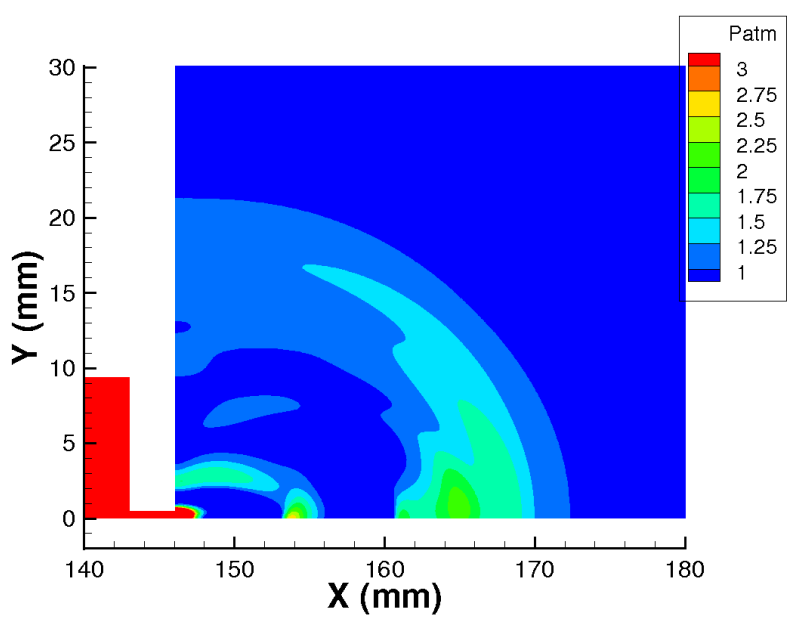

(a) Pressure in atm.

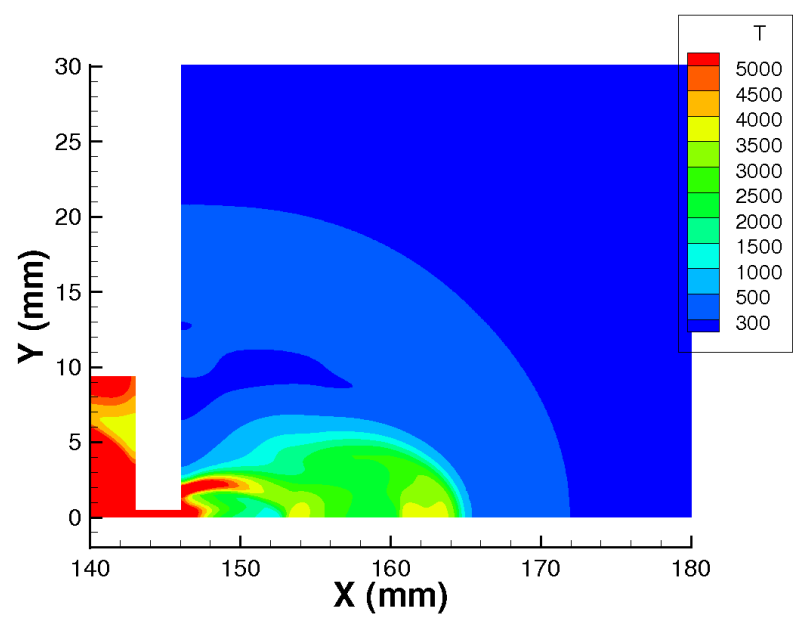

(b) Temperature in Kelvin.

Figure 8. Case S2 pressure and temperature contours at $\mathrm{t}=115 \mu \mathrm{s}$.

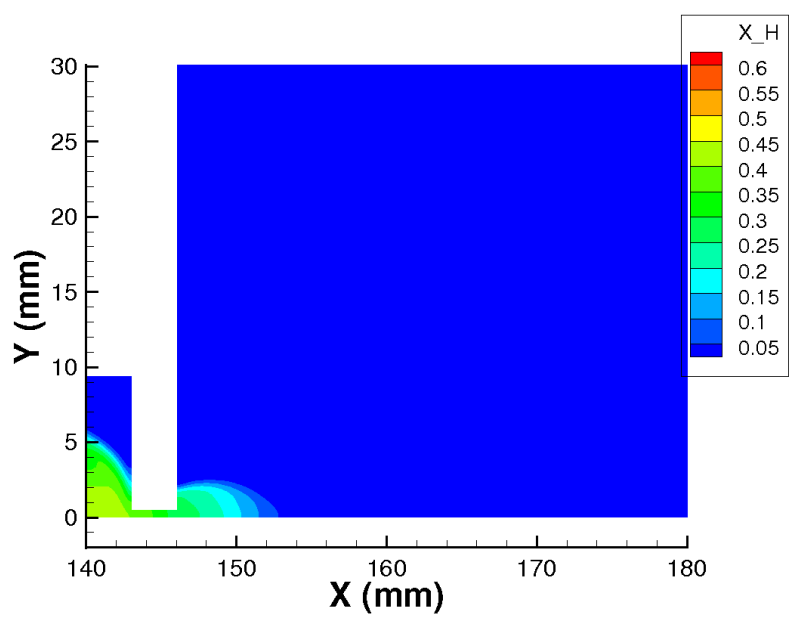

(a) $\mathrm{H}$

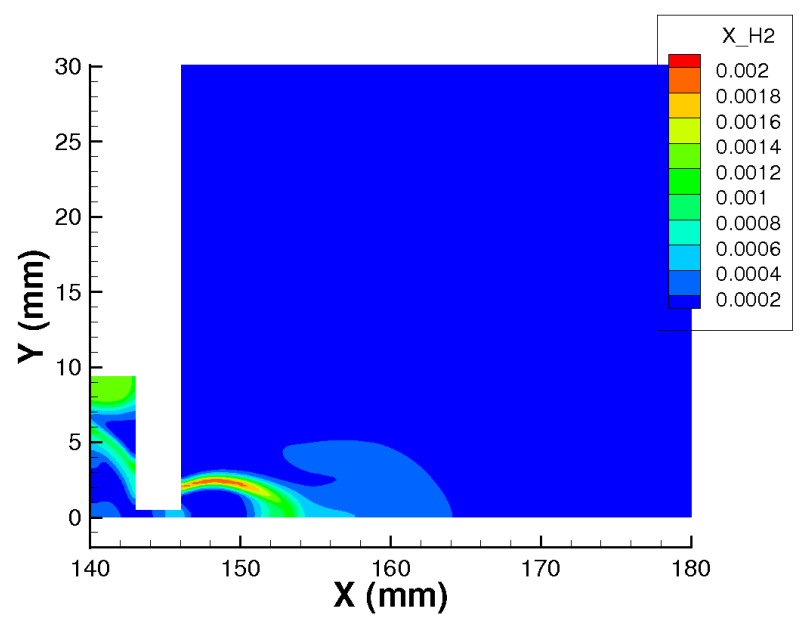

(b) $\mathrm{H}_{2}$

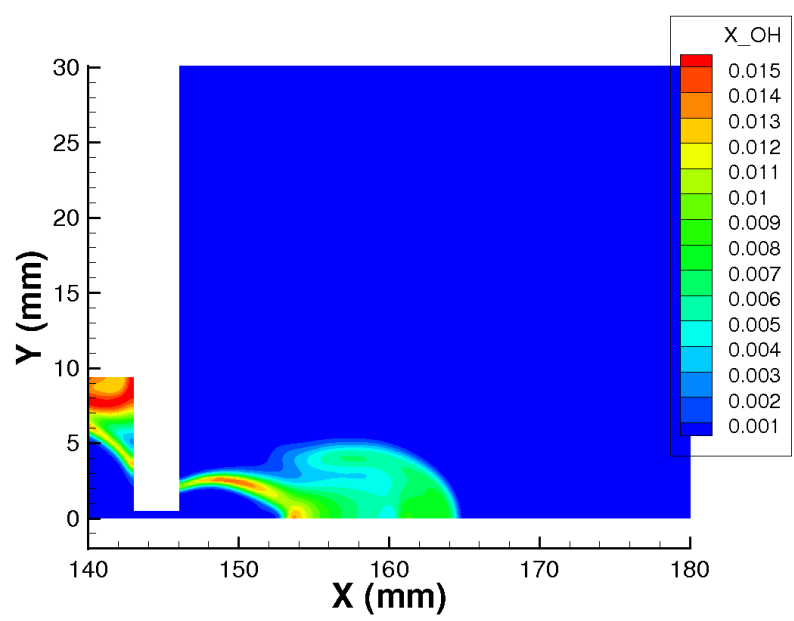

(c) $\mathrm{OH}$

Figure 9. Case S2 mole fractions for selected hydrogen species at $\mathrm{t}=115 \mu \mathrm{s}$. 


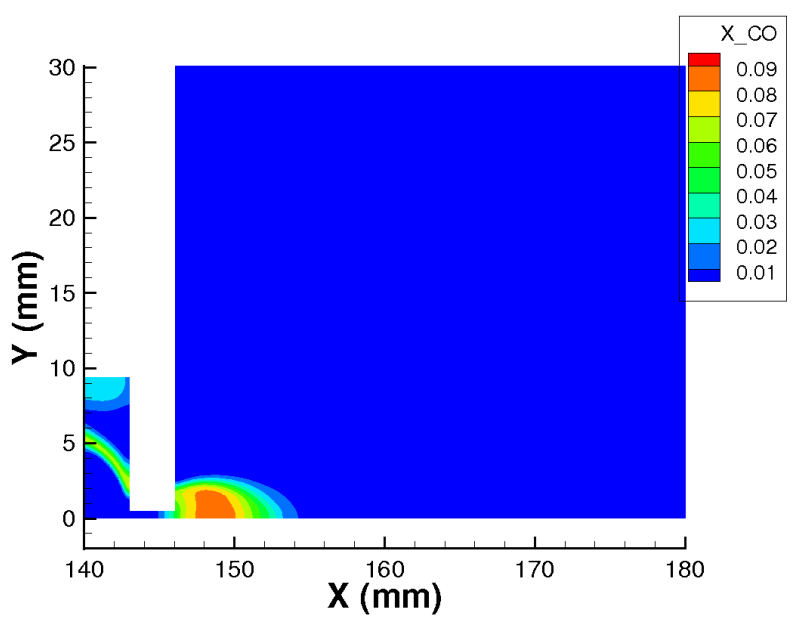

(a) $\mathrm{CO}$

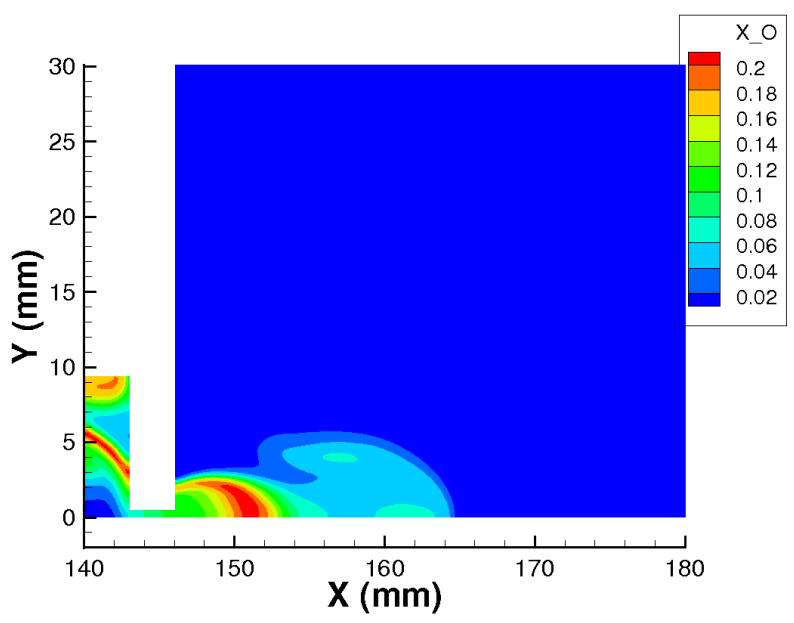

(c) $\mathrm{O}$

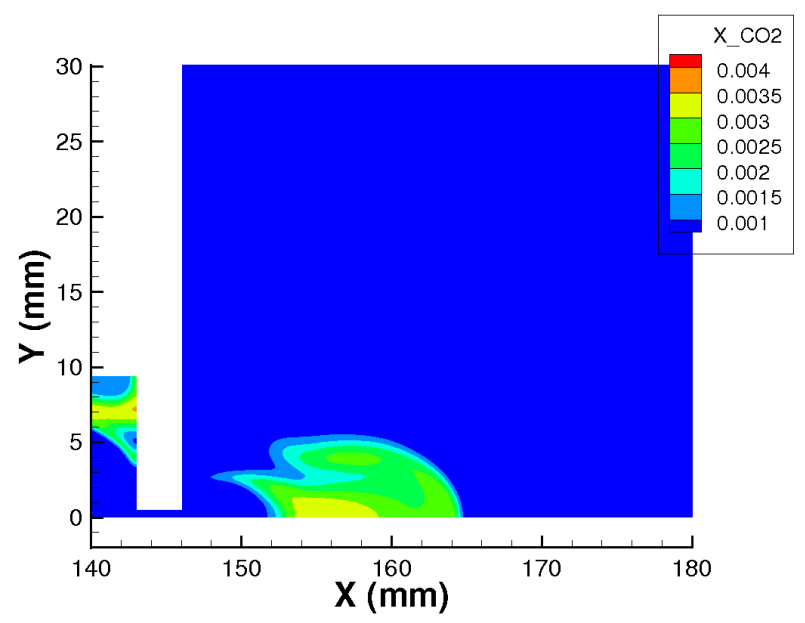

(b) $\mathrm{CO}_{2}$

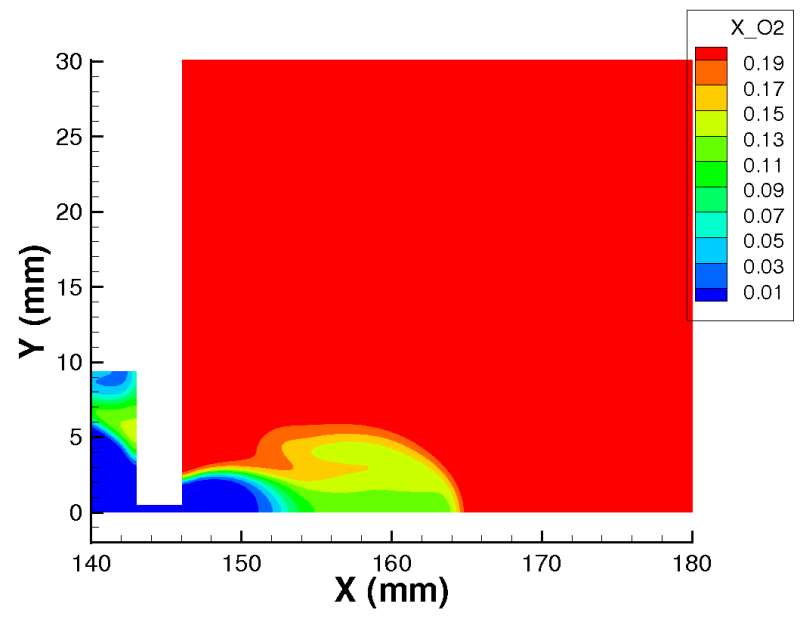

(d) $\mathrm{O}_{2}$

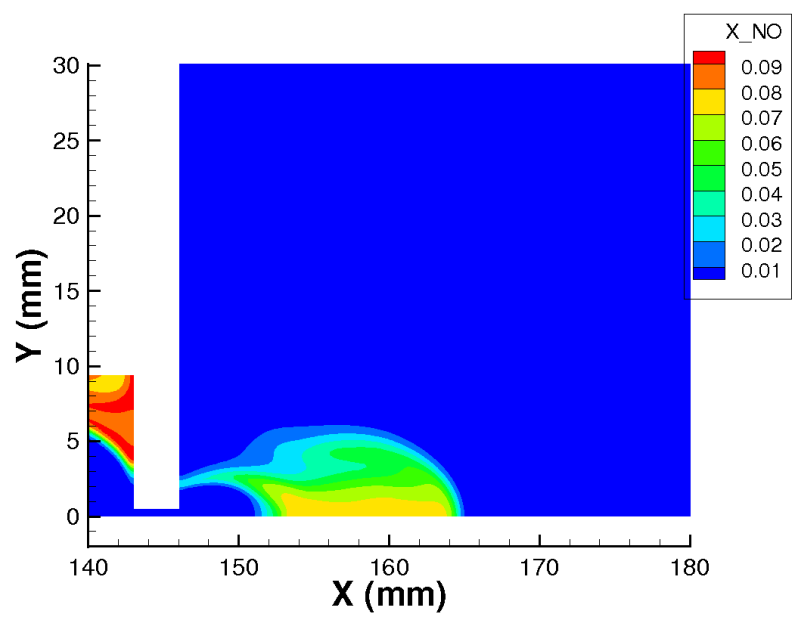

(e) $\mathrm{NO}$

Figure 10. Case S2 mole fractions for selected oxygen species at $\mathrm{t}=115 \mu \mathrm{s}$. 
by simply eliminating species that do not contribute significantly to the plasma-air interaction, thus allowing for a great increase in computational speed. Here we present what could be considered a minimalist model for the chemistry of the plasma-air interaction.

The simulations clearly indicate that all $\mathrm{C}_{x} \mathrm{H}_{y}$ species can be eliminated, as they never present in abundance. Although $\mathrm{CH}$ does not present in the jet, it does appear in significant quantities in the capillary nozzle $(0 \mathrm{~mm} \leq \mathrm{x} \leq 13 \mathrm{~mm})$. However, $\mathrm{CH}_{2}$ does not present significantly even in the nozzle, so could be eliminated. Some of Park's Model can be neglected for ETC application. Although their atomic forms are prevalent, $\mathrm{O}_{2}{ }^{+}, \mathrm{N}_{2}{ }^{+}$, and $\mathrm{NO}^{+}$do not present significantly. The reason for this being that when temperatures are high enough these molecular species tend to dissociate rather than ionize under these conditions.

For 26 chemical species the implicit method has a 29x29 matrix to solve at every grid point, where 29 comes from 26 species plus two velocities plus energy. The elimination of six species reduces the implicit submatrix to $23 \times 23$, a reduction of 312 elements, or a reduction of $60 \%$. Of course all chemical reactions including these species would also be eliminated, resulting in a further increase. The reactions eliminated from Table 1 are 4, 8, 15, 20, 23, 26, 27, 29, 30, 41, 42, 50, and 52-58, leaving a total of 41 reactions. This represents a significant speedup for the code.

\section{Plasma-Air Chemistry in Practical ETC Application}

All previous work on the expansion of the plasma jet and plasma-air chemistry for ETC application has had a major aspect in common: relatively large capillary-wall, or capillary-propellant, spacings. In the case of capillary-propellant spacing, there is typically a desire to inspect the propellant surface after it has been exposed to the plasma as this is highly informative. ${ }^{20}$ It has been found in experiments, however, that for small capillary-propellant distances the propellant is cracked or shattered by the initial pressure wave from the capillary firing, ${ }^{21}$ leading to typical experimental capillary-propellant distances greater than $20 \mathrm{~mm}$. When a large capillary-wall distance is used it is typically because there are pressure sensors located in the wall, as in Case S1, which are easily damaged by the high temperature, velocity and pressure of the jet near the capillary exit, ${ }^{21}$ again leading to larger sample distances.

In real ETC application, the geometry of the plasma jet expansion region is much different. There are a number of different propellant packing options, but they primarily reduce to one of two choices. The first is to pack the chamber with different shape solid propellant blocks or loose propellant grain, leaving crevasses for the ignition plasma to flow through. This packing can leave a small air pocket just outside the capillary exit, or can be right up to the capillary itself. ${ }^{2}$ In fact there are results indicating that for most efficient ETC ignition the capillary-propellant distance should be minimized. ${ }^{22}$

The second method is to have a central channel for plasma to flow through, resulting in a smaller interaction region but a more uniform burn. ${ }^{22}$ This method is similar to the ignition method of solid rocket motors.

With the first method, it is easy to see that plasma-air chemistry will have little effect, as there is little air present in the regions between the tightly packed propellant blocks. The primary chemical mechanism will be the interaction between the capillary plasma and the propellant surface and ablated propellant gases and particulates. A similar conclusion is not so straight forward for the second method. As the plasma advances down the tube the plasma-air reaction zone will be pushed with it, which should severely limit the high temperature air-propellant reaction zone.

Evaluation of Case S1 at $\mathrm{t}=15 \mu \mathrm{s}$ indicates that if the capillary-propellant distance is small $(<10$ $\mathrm{mm}$ ), then there will be little to no plasma-air chemistry before the plasma-propellant interaction begins. Furthermore, any ionized, or otherwise affected, air species that are present will be transient, as the reaction zone will sweep past the propellant surface followed by the capillary plasma jet. The above information for practical ETC application, along with the results for plasma-air reaction rates from Case S1, suggest that in real ETC application the plasma-air interaction is perhaps completely negligible.

To test the importance of the plasma-air interaction in the second propellant packing option a simulation is conducted using the reduced chemistry model outlined above. The geometry for this simulation, labeled below as Case S3, is taken from Beyer et al. ${ }^{22}$ The capillary inflow is the same used as in Case S1 and Case S2. In the experiment a tube $(6.3 \mathrm{~mm}$ diameter, $152 \mathrm{~mm}$ length) was inserted into the cylindrical propellant grain. The tube had eight sets of four holes to allow hot ignition gases to escape. Gas flows into the tube from the capillary and exits out the 32 vent holes.

To simulate this geometry the eight sets of holes are converted to eight axisymmetric slits of equal surface area, giving an individual slit width of $0.4 \mathrm{~mm}$. A cell spacing of $\Delta \mathrm{x}=0.05 \mathrm{~mm}$ is used due to the small size 
of the outflow slits. A time step of $\Delta \mathrm{t}=5 \times 10^{-9} \mathrm{~s}$ is used. In the experiment there was no capillary nozzle, thus the simulation geometry is simply an axisymmetric rectangle $3.15 \mathrm{~mm}$ by $152 \mathrm{~mm}$ with outflow slits every $16.9 \mathrm{~mm}$, with the capillary inflow at $\mathrm{x}=0 \mathrm{~mm}$.

All flow properties are output at each of the outflow slits over time. Figure 11 shows pressure, temperature, and significant species exiting the first outflow slit $(\mathrm{x}=16.9 \mathrm{~mm})$. Species data is presented in terms of number density. We see a strong initial spike of $\mathrm{N}_{2}$ and $\mathrm{O}_{2}$ as the precursor shock is pushed past the outflow slit. As time progresses we see a steady rise in $\mathrm{N}, \mathrm{O}$, and $\mathrm{NO}$ as the temperature rises, while $\mathrm{N}^{+}$and $\mathrm{O}^{+}$remain negligible. When the temperature surpasses $10,000 \mathrm{~K}$ the air species have passed the slit and the capillary species have arrived. At this first slit we see a clear distinction between the precursor shock and the plasma jet. For small capillary-sample distances the high temperature gas reaching the propellant surface will be primarily composed of the capillary species, with little plasma-air chemistry taking effect.

Evaluating the outflow data at the remaining seven slits yields much insight. As we approach the slit farthest from the capillary we see the distinction between the precursor shock's air species and the capillary's plasma species disappear. Outflow data for the final slit $(\mathrm{x}=135.2 \mathrm{~mm})$ show that the temperature is a few hundred Kelvin lower than the inflow slit due to the chemical reactions happening in the tube. There are also fewer ionic species, but a higher abundance of atomic species. Essentially we are seeing a similar effect at the later slits as we did in Case S2 with the plasma holding chamber; more plasma-air mixing alters the chemistry of the jet.

This difference in species composition could lead to a different ignition mechanism for the propellant located at the holes further down the tube. The importance of the chemical composition of the plasma to the PPI ignition process is not well known, and is the focus of future work by the authors.

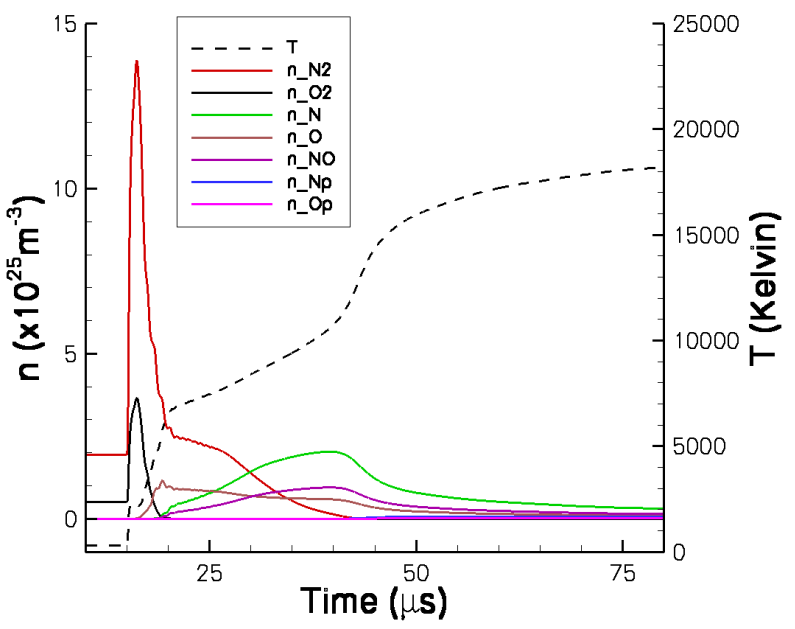

(a) Significant air species and temperature.

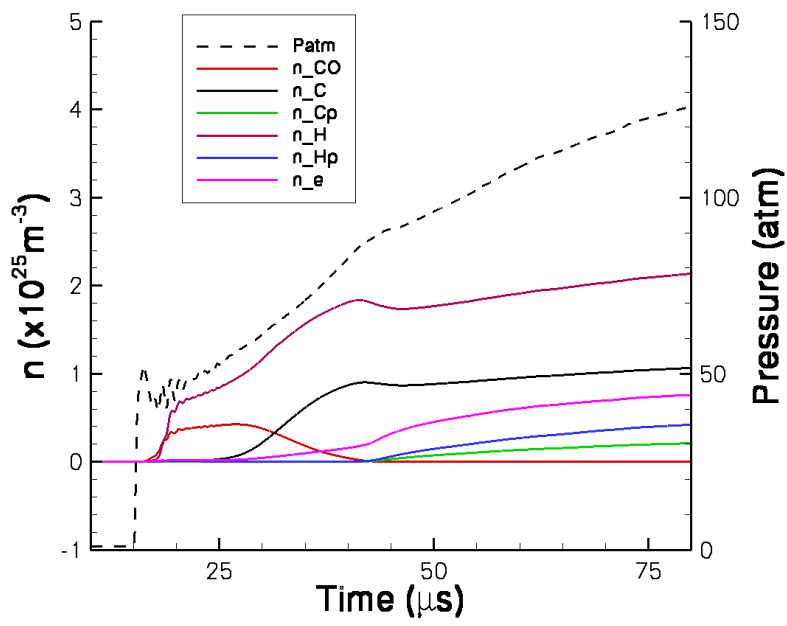

(b) Significant hydrocarbon species and pressure.

Figure 11. Outflow data for the first slit at $\mathrm{x}=16.9 \mathrm{~mm}$ in Case S3.

\section{Conclusion}

Presented was a plasma-air chemistry model designed and tested for ETC application. The results of these simulations allow further refinements to the chemistry model, allowing for the possible elimination of some low abundance species and a decrease in computational time.

There are two major conclusions from this work. Direct comparison of Case S1 and Case S2 clearly indicate that there are significant differences between the primary and secondary jets in the referenced experiments. Differences include jet pressure, temperature and chemical composition. We thus conclude that any experiments to measure the species present in the plasma jet must be very carefully designed, and that the use of a plasma holding chamber is not a viable option as it will not produce results representative of species present in the primary jet.

Secondly, an analysis of Case S1 indicates that for capillary-sample distances less than approximately 10 $\mathrm{mm}$ the plasma-air chemistry may be entirely negligible. A simulation of a practical ETC ignition mechanism 
was conducted to evaluate this hypothesis.

This work is part of a larger attempt to model and study the plasma-propellant interaction. The results of these simulations and others using the model developed will allow for better estimates of the plasma composition in the plasma-propellant interaction, and thus better model results.

\section{Acknowledgments}

The authors gratefully acknowledge the financial support by the Army Research Office, Grant No. W911NF-04-1-0251 (Dr. Ralph Anthenien, technical monitor). This work is also supported by the FrancoisXavier Bagnound Foundation. Porwitzky would also like to thank Tom Schwartzentruber for many helpful discussions and suggestions regarding CFD techniques, as well as David Berger for the data stripping code.

\section{References}

${ }^{1}$ Koleczko, A., Ehrhardt, W., Kelzenberg, S., and Eisenreich, N., "Plasma ignition and combustion", Prop. Explos. Pyrotech., vol. 26, pp. 75-83, 2001.

${ }^{2}$ Dyvik, J., Herbig, J., Appleton, R., O'Reilly, J., and Shin, J., "Recent Activities in Electrothermal Chemical Launcher Technologies at BAE Systems", IEEE Trans. on Magnetics. vol. 43, no. 1, pp. 303-307, January 2007.

${ }^{3}$ Keidar, M., and Boyd, I. D., "Ablation study in the capillary discharge of an electrothermal gun", Journal of Applied Physics, vol. 99, 053301, 2005.

${ }^{4}$ Porwitzky, A. J., Keidar, M., and Boyd, I. D., "Modeling of the Plasma-Propellant Interaction", IEEE Trans. on Magnetics. vol. 43, no. 1, pp. 313-317, January 2007

${ }^{5}$ Scalabrin, L. C., and Boyd, I. D., "Development of an Unstructured Navier-Stokes Solver For Hypersonic Nonequilibrium Aerothermodynamics", 38th AIAA Thermophysics Conference, 6-9 June 2005, Toronto, Canada.

${ }^{6}$ Scalabrin, L. C., and Boyd, I. D., "Numerical Simulation of Weakly Ionized Hypersonic Flow for Reentry Configuations", 9th AIAA/ASME Joint Thermophysics and Heat Transfer Conference, 5-8 June 2006, San Francisco, California.

${ }^{7}$ Nusca, M. J., Anderson, W. R., and McQuaid, M. J., "Multispecies Reacting Flow Model for the Plasma Efflux of an ETC Ignited-Application to an Open-Air Plasma Jet Impinging on an Instrumented Probe," ARL-TR-3227, July 2004.

${ }^{8}$ Nusca, M. J., McQuaid, M. J., and Anderson, W. R., "Numerical Simulation of an Open-Air Plasma Jet Using a MultiSpecies Reacting Flow CFD Code", 31st AIAA Plasmadynamics and Lasers Conference, 19-22 June 2000, Denver, Colorado.

${ }^{9}$ Sutton, K., and Gnoffo, P. A., "Multi-Component Diffusion with Application to Computational Aerothermodynamics", 7th AIAA/ASME Joint Thermophysics and Heat Transfer Conference, June 15-18, 1998, Albuquerque, New Mexico.

${ }^{10}$ Keidar, M., Boyd, I. D., Williams, A., and Beyer, R., "Ablation Study in a Capillary Sustained Discharge", IEEE Transactions on Magnetics, vol. 43, no. 1, pp. 308-312, January 2007.

${ }^{11}$ Li J., Litzinger, T. A., Das, M., and Thynell, S. T., "Study of Plasma-Propellant Interaction During Normal Impingement", Journal of Propulsion and Power, Vol. 22, No. 5, September-October 2006.

${ }^{12} \mathrm{Li}$ J., Litzinger, T. A., Das, M., and Thynell, S. T., "Recombination of Electrothermal Plasma and Decomposition of Plasma-Exposed Propellants", Journal of Propulsion and Power, Vol. 22, No. 6, November-December 2006.

${ }^{13}$ Gupta, R. N., Yos, J. M., Thompson, R. A., Lee, K., "A Review of Reaction Rates and Thermodynamic and Transport Properties for an 11-Species Air Model for Chemical and Thermal Nonequilibrium Calculations to 30000K," NASA Reference Publication 1232, 1990

14 "GRI-Mech Home Page", http://www.me.berkeley.edu/gri_mech/.

${ }^{15}$ Chang, Y., and Ordonez, C. A., "Semi-Empirical Ionization and Excitation Rate Coefficients for Hydrogen, Helium, and Oxygen Atoms and Ions in Plasmas", AIP Conference Proceedings, 10 June 1999, vol. 475, pp. 887-890.

${ }^{16}$ Chang, Y., and Ordonez, C. A., "Generalization of the Arrhenius relation and ionization reaction rates for carbon atoms and ions in plasmas", Chemical Physics, vol. 231, pp. 27-30, 1998.

${ }^{17}$ Field, F. H., and Franklin, J. L., "Electron Impact Phenomena and the Properties of Gaseous Ions," Academic Press, New York, Revised Edition, 1970.

${ }^{18}$ McBride, B. J., and Gordon, S., "Computer Program for Calculation of Complex Chemical Equilibrium Compositions and Applications; II. Users Manual and Program Description," NASA Reference Publication 1311, June 1996.

${ }^{19} \mathrm{Li}$, J., private communication, 29 March 2007.

${ }^{20}$ Pesce-Rodriguez, R. A., and Beyer, R. A., "A Theory of Plasma-Propellant Interactions", ARL-TR-3286, September 2004.

${ }^{21}$ Li J., Litzinger, T. A., and Thynell, S. T., "Interaction of Capillary Plasma with Double-Base and Composite Propellants", Journal of Propulsion and Power, Vol. 20, No. 4, July-August 2004.

${ }^{22}$ Beyer, R., Brant, A. L., "Plasma Ignition in a 30-mm Cannon", IEEE Transactions on Magnetics, vol. 43, no. 1, pp. 294-298, January 2007. 